ARTICLE

\title{
Recognition of non-CpG repeats in Alu and ribosomal RNAs by the Z-RNA binding domain of ADAR1 induces $A-Z$ junctions
}

Parker J. Nichols (iD 1, Shaun Bevers ${ }^{1,2}$, Morkos Henen ${ }^{1,3}$, Jeffrey S. Kieft ${ }^{1,4}$, Quentin Vicens (iD ${ }^{1,5 凶} \&$ Beat Vögeli (10) ${ }^{1,5}$

Adenosine-to-inosine (A-to-I) editing of eukaryotic cellular RNAs is essential for protection against auto-immune disorders. Editing is carried out by ADAR1, whose innate immune response-specific cytoplasmic isoform possesses a Z-DNA binding domain $(Z \alpha)$ of unknown function. $Z \alpha$ also binds to $C p G$ repeats in RNA, which are a hallmark of Z-RNA formation. Unexpectedly, $Z \alpha$ has been predicted - and in some cases even shown - to bind to specific regions within mRNA and rRNA devoid of such repeats. Here, we use NMR, circular dichroism, and other biophysical approaches to demonstrate and characterize the binding of $Z \alpha$ to mRNA and rRNA fragments. Our results reveal a broad range of RNA sequences that bind to $Z \alpha$ and adopt Z-RNA conformations. Binding is accompanied by destabilization of neighboring A-form regions which is similar in character to what has been observed for B-ZDNA junctions. The binding of $Z \alpha$ to non- $C p G$ sequences is specific, cooperative and occurs with an affinity in the low micromolar range. This work allows us to propose a model for how $Z \alpha$ could influence the RNA binding specificity of ADAR1.

\footnotetext{
${ }^{1}$ Department of Biochemistry and Molecular Genetics, University of Colorado Denver School of Medicine, Aurora, CO 80045, USA. ${ }^{2}$ Colorado Schoo of Mines, Golden, CO 80401, USA. ${ }^{3}$ Faculty of Pharmacy, Mansoura University, Mansoura 35516, Egypt. ${ }^{4}$ RNA BioScience Initiative, University of Colorado Denver School of Medicine, Aurora, CO 80045, USA. ${ }^{5}$ These authors jointly supervised this work: Quentin Vicens, Beat Vögeli.

凶email: quentin.vicens@cuanschutz.edu; beat.vogeli@cuanschutz.edu
} 
$\mathrm{D}$ istinguishing between self and non-self RNA is a hallmark of the innate immune system. In humans, self RNAs are edited by an adenosine deaminase that acts on RNA (ADAR1), which converts some adenosines to inosines ${ }^{1-3}$. Because inosines tend to disrupt double-stranded regions, such RNAs are not recognized by PKR, MDA5, and RIG-I, which are enzymes that trigger an immune response through binding to foreign and therefore unedited double-stranded regions ${ }^{4,5}$.

ADAR1 is constitutively expressed in most cells as a stable p110 isoform localized in the nucleus ${ }^{6-8}$. Upon invasion by a pathogen, the cell launches an interferon (IFN) response, resulting in the expression of a longer p150 isoform, which contributes to resisting the infection by editing self RNAs in the cytoplasm ${ }^{6,9}$ (Fig. 1a). A-to-I editing is therefore augmented during the IFN response, primarily through the action of ADAR1p150 ${ }^{4}$.

Although infections lead to a massive increase in editing events, A-to-I changes do not occur nonspecifically. Approximately $90 \%$ of A-to-I editing events occur at primate-specific Alu elements ${ }^{10-12}$, the most ubiquitous family of short-interspersed repeats within the human genome ${ }^{13}$. Alu elements recently have been shown to be one of the primary activators of IFN in relapsing-remitting multiple sclerosis ${ }^{14}$ and enrichment of Alu RNAs may be a common factor of autoimmune diseases ${ }^{15,16}$. These observations may directly relate to recent findings that host Alu RNAs are one of the primary activators of RIG-I during Kaposi's sarcoma-associated herpesvirus infection ${ }^{17,18}$. This suggests that an essential role of ADAR1-and ADAR1p150 in particular-is to edit Alu elements so that activation of dsRNA sensors is prevented. ADAR1 is therefore part of the strategy to modulate the delicate balance between turning the IFN response on or off.

ADAR1p150 catalyzes A-to-I editing within Alu "foldback" structures, where an Alu element pairs with an inverted Alu element located a few hundred nucleotides away on the same $\mathrm{RNA}^{4,19}$. How ADAR1p150 achieves this level of specificity is unknown. Part of the answer likely lies within its N-terminus, which comprises a $Z \alpha$ and a $Z \beta$ domain separated by a linker of $\sim 100$ amino acids. While $\mathrm{Z} \beta$ is present in both isoforms, $\mathrm{Za}$ is present only in the IFN-induced ADAR1p150. Za is a member of a family of helix-turn-helix domains that recognize the unusual
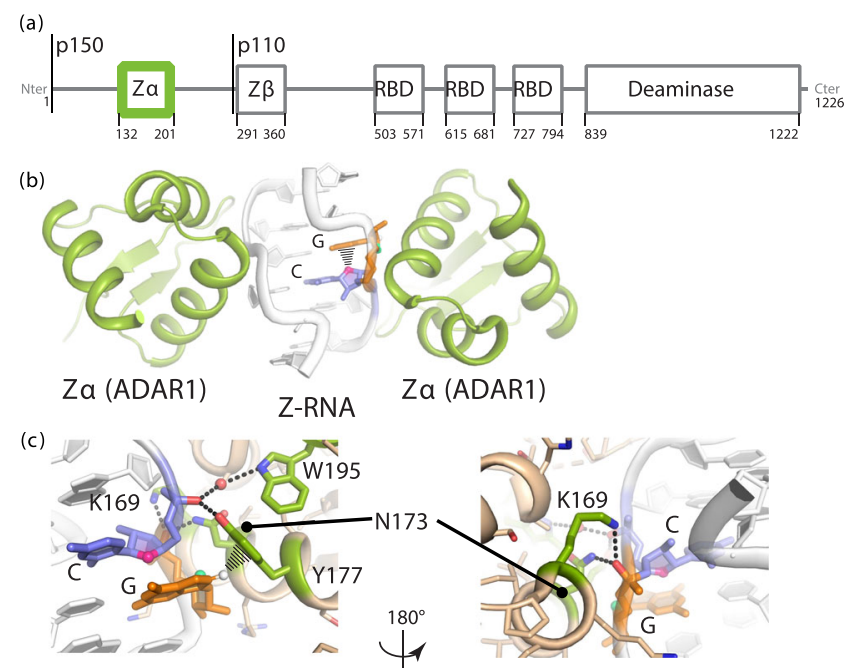

Fig. 1 The Z $\alpha$ domain of ADAR1p150 binds to Z-RNA. a Domain organization of ADAR1: $Z \alpha$ and $Z \beta$ are structurally homologous helix-turnhelix DNA-binding domains, RBD stands for double-stranded RNA binding domain. Both isoforms are indicated. $\mathbf{b}$ Crystal structure of $(\mathrm{CpG})_{3}$ bound to Z $\alpha$ from ADAR1 (PDB ID: 2GXB) ${ }^{25}$. c Close-up of the RNA-protein interface. geometry of the Z-conformation in DNA or RNA and bind to five base pairs in a symmetrical fashion (Fig. 1b) ${ }^{20,21}$. Based on the structural similarity between Z-DNA and Z-RNA, it was proposed and verified that $\mathrm{Za}$ binds to CpG-only RNAs with a dissociation constant $\left(\mathrm{K}_{\mathrm{d}}\right)$ of $\sim 9 \mathrm{nM}^{22,23}$. Furthermore, the addition of $\mathrm{CpG}$ repeat sequences to ADAR1p150 substrates significantly increases the deamination of neighboring adenosines $^{24}$. Whether $\mathrm{Za}$ also binds to less idealized sequences, with what $K_{d}$, and following what binding process are fundamental questions that remain to be answered.

The crystal structure of $\mathrm{Za}$ in complex with a $(\mathrm{CpG})_{3} \mathrm{RNA}$ duplex showed that binding specificity is achieved through a critical tyrosine residue (Tyr177), which makes a C-H... $\pi$ interaction with the syn purine in the CpG Z-step (Fig. 1c) ${ }^{25,26}$. Tyr177 is positioned to interact with Z-RNA through a network of interactions involving other amino acids (notably Lys169, Asn173, and Trp195; Fig. 1c), which cause a $60 \%$ reduction in A-to-I editing levels when they are mutated $(5,27,28)$. This reduction in editing leads to the Aicardi-Goutières syndrome ${ }^{28}$, a neurodevelopmental disorder characterized by hyperactive immune responses. $\mathrm{Za}$ is clearly important for the integrity of the editing process, but how does that relate to its ability to bind Z-DNA and/or Z-RNA?

Although most studies of $\mathrm{Za}$ were done with $\mathrm{CpG}$ repeats, $\mathrm{Za}$ can also recognize TpA, CpA, GpC, and TpG in DNA ${ }^{20,29}$. This observation indicates that many dinucleotide sequences can adopt a Z-conformation, as observed in RNA for an even broader range of sequences (Supplementary Fig. 1) ${ }^{30}$. Although non-CpG sequences within DNA bind to $\mathrm{Za}$, the resulting complexes are less stable compared to $\mathrm{CpG}$ repeats ${ }^{23}$. Intriguingly, the adoption of Z-conformations within the context of larger dsDNA stretches requires the formation of $\mathrm{B}-\mathrm{Z}$ junctions, where the $\mathrm{B}$-DNA regions flanking the $Z$-forming sequence become destabilized by $\mathrm{Za}$ binding, and nucleotides adjacent to the Z-DNA sequence flip out in order to create continuous base-stacking between the Band Z-DNA ${ }^{31-34}$. In such conformations, four $\mathrm{Za}$ molecules are bound to an eight base-pair stretch, indicating that $\mathrm{Za}$ can bind to a variable number of base pairs depending on the context ${ }^{31}$. While the formation of equivalent $\mathrm{A}-\mathrm{Z}$ junctions in RNA has been shown to be possible by fluorescence studies ${ }^{35}$, our knowledge of the sequence preferences and contexts for the formation of such conformations upon $\mathrm{Z} \alpha$ binding is limited. Within RNA, some of the sequence combinations (especially UpG and UpA repeats) have been predicted to shift to Z-RNA within the heavily edited Alu foldback structures ${ }^{36}$. In further support of a broad recognition of RNA sequences by $\mathrm{Za}$, pull-down assays revealed that $\mathrm{Za}$ binds to ribosomal stem-loops sometimes devoid of $\mathrm{CpG}$ repeats ${ }^{37}$. This broader RNA sequence specificity is in support of the Za-mediated increase in ADARl's specificity and activity proposed by Rich ${ }^{24}$, and could also explain the recently described surge in mouse anti-viral response upon sensing endogenous retroviral elements by the $\mathrm{Za}$ domain of Z-DNAbinding protein $1^{38}$.

We hypothesize that the $>10,000$ editing sites in the human transcriptome $e^{11,12}$ are associated with widespread Z-RNA formation at $\mathrm{CpG}$ as well as non-CpG sequences within Alu foldbacks. To begin to address this possibility, we applied NMR, circular dichroism (CD), isothermal titration calorimetry (ITC), and analytical ultracentrifugation (AUC) to characterize the binding of $\mathrm{Za}$ to RNA fragments with various frequencies of $\mathrm{CpG}$ repeats. We demonstrate binding of $\mathrm{Za}$ at specific sites on a fragment from an Alu foldback rich in UpG steps (AluSx1Jo; ${ }^{36}$ ) and on hairpins from bacterial and human ribosomal RNAs that contain various types of $\mathrm{YpR}$ repeats $(\mathrm{Y}=$ pyrimidine, $\mathrm{R}=$ purine $)^{37}$. Our NMR results show that binding results in the formation of A-Z junctions in these RNAs and that RNAs with regions of low helical stability adjacent to a $\mathrm{Z}$-forming sequence 
are better Z-RNA adopters. For the Alu fragment and for the $E$. coli h43 hairpin in particular, we further determine that two $\mathrm{Za}$ molecules bind every four to five base pairs, and that binding is cooperative, with $K_{D}$ values of $1-9 \mu \mathrm{M}$ and $40-110 \mathrm{nM}$. In sum, when binding to AluSx1Jo, Za adopts a conformation that has characteristics of both a B-Z DNA junction and the $(\mathrm{CpG})_{3}$ RNA repeat. Overall, our work offers a rationale for earlier observations that ADAR1 binds in multiple steps to double-stranded RNA regions often flanked by regions rich in non-Watson-Crick pairs ${ }^{39,40}$. This study also provides a framework for better understanding widespread and pervasive editing in cells.

\section{Results}

$\mathrm{Za}$ induces $\mathrm{A}-\mathrm{Z}$ junctions within an AluSx1Jo foldback fragment and ribosomal hairpin $\mathbf{h} 43$. The core model systems of our study are an element from the AluSx1Jo foldback within the Cathepsin S (CTSS) gene on human chromosome 1, as well as hairpin 43 from the small subunit of the E. coli ribosome comprising hairpin h43 (Fig. 2a). This region of AluSx1Jo had been predicted to adopt a Z-conformation ${ }^{36}$, and h43 had been reported to bind to $\mathrm{Za}$ in vitro ${ }^{37}$. The AluSx1Jo region comprises predominantly $\mathrm{UpG}$ repeats, but also one $\mathrm{CpG}$, one $\mathrm{CpA}$, and one UpA dinucleotide steps. Hairpin h43 contains a symmetrical (or 'canonical') $\mathrm{CpG}$ step together with several UpG and CpA steps. Based on current knowledge of $\mathrm{Za}$ recognition, it is not immediately apparent how these two RNAs could adopt the Z-RNA conformation required for $\mathrm{Za}$ binding.

Using chemically synthesized RNA fragments for AluSxlJo, $\mathrm{h} 43$, and the control sequences $(\mathrm{CpG})_{3}$ and two $\mathrm{A}-\mathrm{Z}$ junctions, we first carried out $C D$ experiments, which have traditionally been used to monitor transitions to the Z-conformation in DNA and $\mathrm{RNA}^{22,41}$. Upon titrating increasing amounts of $\mathrm{Za}$ to the control $(\mathrm{CpG})_{3}$ fragment (from 12:1 to 1:6 RNA:Za), we observed the characteristic decrease in the A-form peak at $266 \mathrm{~nm}$, the appearance of a peak at $285 \mathrm{~nm}$, and the flip from negative to positive at $295 \mathrm{~nm}$ (Fig. 2b, full titration shown in Supplementary Fig. 2). Together, these three changes were indicative of a conversion to the $\mathrm{Z}$-conformation ${ }^{22}$, and are unlikely to be due to a conformational change in $\mathrm{Za}$ upon binding RNA as our ${ }^{15} \mathrm{~N}$ HSQC titration indicates binding only results in minor rearrangements to the RNA binding residues of $\mathrm{Za}$ (Supplemental Figs. S13 and S14). However, our selected test RNAs had diverse sequence context and likely did not fully adopt the Zconformation. Performing the same experiment with RNAs which form $A-Z$ junctions (A-Z 1 is the RNA version of a previously characterized $\mathrm{B}-\mathrm{Z}$ junction ${ }^{31}$, and $\mathrm{A}-\mathrm{Z} 2$ has been shown by fluorescence studies to adopt an A-Z junction ${ }^{35}$ ),

(a)
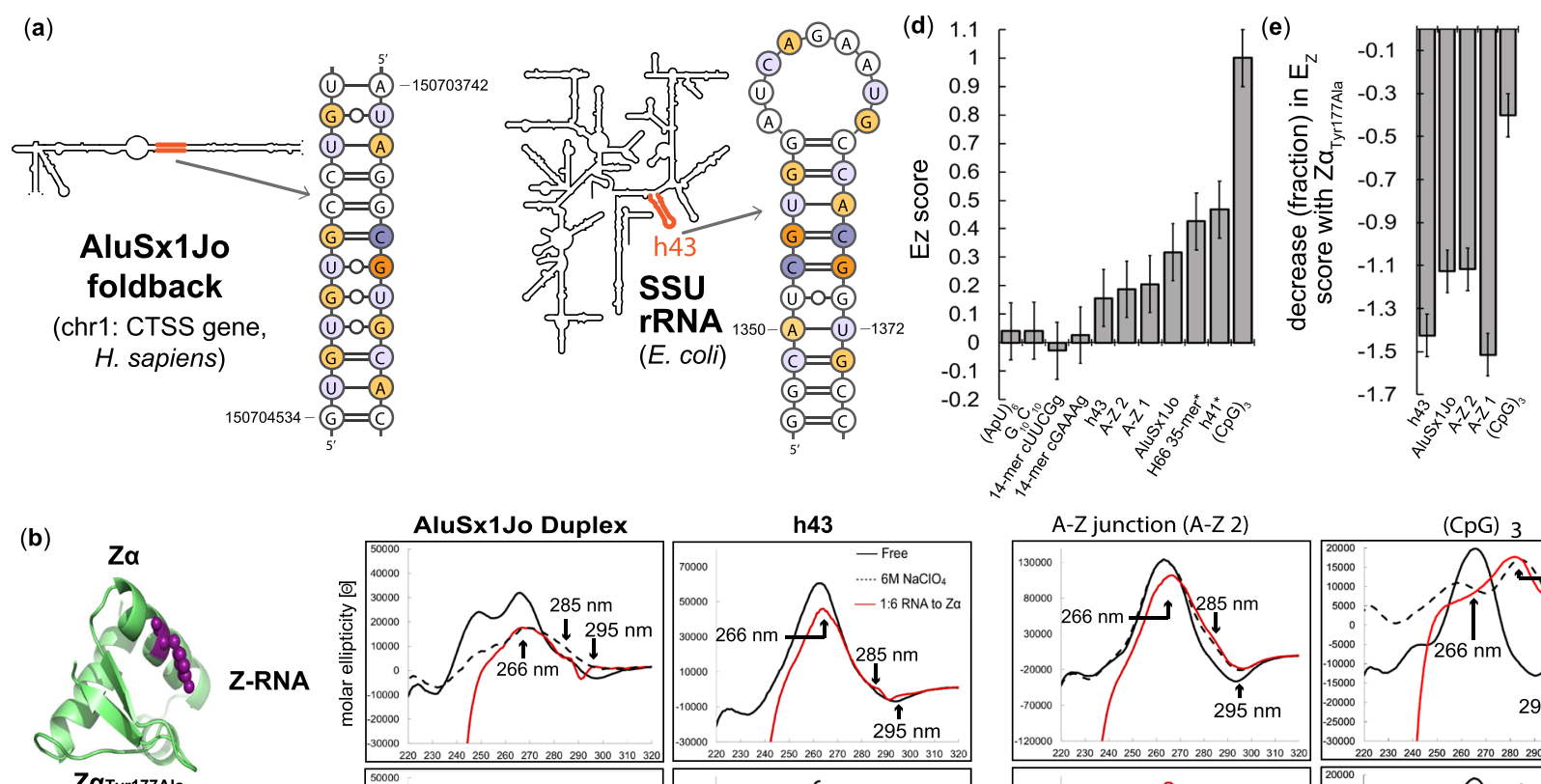

Z-RNA

(c)
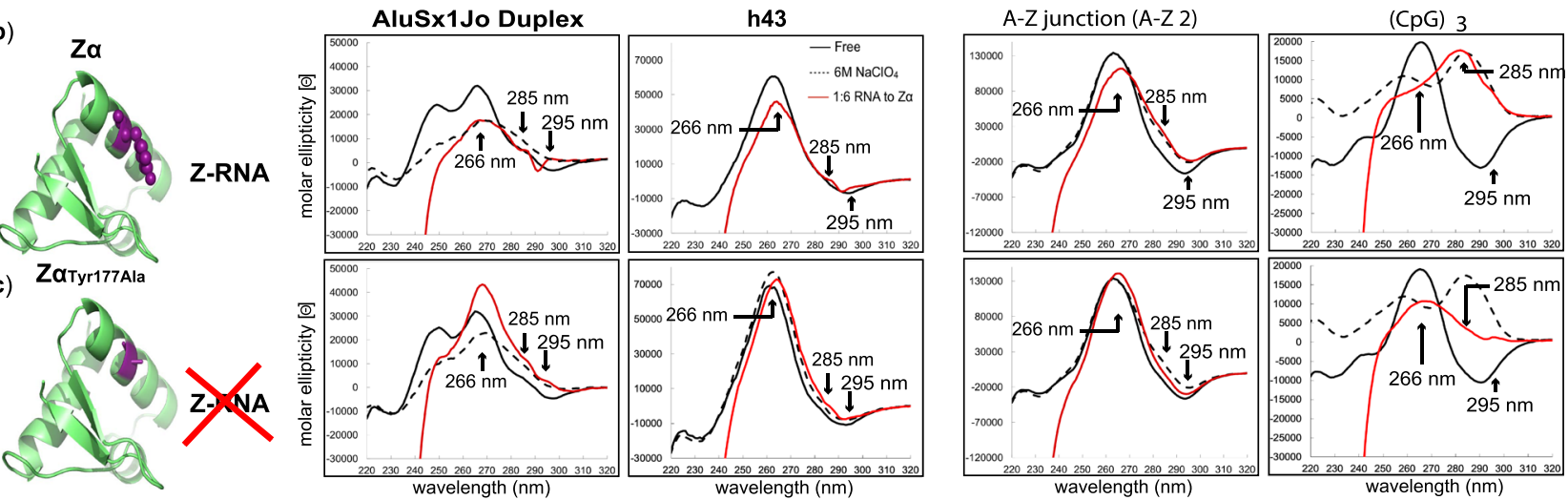

Fig. 2 Z $\alpha$ induces a partial Z-conformation in AluSx1Jo and h43. a Location of AluSx1Jo and h43 on secondary structure diagrams of the CTSS gene (Chromosome 1) from $H$. sapiens and the small subunit ribosomal RNA from $E$. coli. For $h 43$, the first three $G=C$ base pairs were engineered for added stability. In this and subsequent figures, $\mathrm{CpG}$ and YpR steps are shown in dark (CpG) and light (non-CpG YpR) shades of purple/orange colors. b CD spectra of the AluSx1Jo and h43 RNAs in absence of protein (black) and at the 1:6 RNA:Z $\alpha$ ratio (red), at which binding is saturated. Controls: $6 \mathrm{M} \mathrm{NaClO}_{4}$ (dotted line), ionic condition that promotes Z-RNA formation of $\mathrm{CpG}$ repeats ${ }^{57}$; A-Z junction ${ }^{35}$ (second to right-most panel), which is an RNA that has a $(\mathrm{CpG})_{6}$ sequence followed by an A-RNA forming sequence, and $(\mathrm{CpG})_{3}$ (right-most panel), which is fully converted to Z-RNA at a 1:2 RNA:Z $\alpha$ ratio. c Same as $\mathbf{b}$, but with $Z \alpha_{\text {Tyr177Ala }}$ instead of wild-type $Z \alpha$. $\mathbf{d} E_{Z}$ scores quantifying the extent of Z-conformation for the following fragments: $(A p U)_{6}, G_{10} C_{10}, 14 m e r$ cUUCGg, cGAAAg tetraloop (negative controls); h43 from E. coli; AluSx1Jo; H66 35mer from H. sapiens; (CpG) 3 (positive control). e Reduction in $E_{Z}$ score for AluSx1Jo, h43, and (CpG)3 RNAs (expressed as a fraction) when Z $\alpha_{\text {Tyr177Ala }}$ is used instead of Z $\alpha .{ }^{*}$ indicates that RNA forms a duplex as determined by AUC when stem-loop was expected (Supplementary Fig. 5). An error of 0.1 was determined to be appropriate for the calculated $E_{Z}$ scores by taking into account the difference between the $(\mathrm{CpG})_{3}$ and $(\mathrm{CpG})_{6}$ RNAs (which theoretically both have an $E_{Z}$ score of 1 ) and the difference in the $E_{Z}$ score between repeat measurements on $\mathrm{h} 43 \mathrm{E}$.coli. All other $E_{Z}$ scores were determined from one CD measurement. 
we observed instead a reduction of the peak at $266 \mathrm{~nm}$ and smaller-in-magnitude increases to the molar ellipticities values at 285 and $295 \mathrm{~nm}$ (Fig. 2b, Supplementary Fig. S2). Therefore, the $\mathrm{CD}$ spectra of A-Z junctions is population-weighted depending on the amount of Z-conformation adopted by a particular RNA.

We also carried out $\mathrm{CD}$ experiments with a $\mathrm{Za}$ construct where Tyr177 was mutated to alanine $\left(\mathrm{Za}_{\text {Tyr177Ala }}\right)$-resulting in impaired Z-RNA binding capabilities ${ }^{37,42}$ - which led to smaller absolute magnitudes of the shifts at these three wavelengths for the $(\mathrm{CpG})_{3}$ RNA and resulted in a growth of the molar ellipticity at $266 \mathrm{~nm}$ for the A-Z junction (Fig. 2c). This growth likely occurred because $Z \alpha_{\text {Tyr177Ala }}$ can still bind to RNA, without causing the conformation switch to the Z-conformation (discussed later and shown by NMR in Supplementary Fig. S9).

A change in the CD spectra similar to that for the control A-Z junction was observed for AluSx1Jo and h43 as the $\mathrm{Za}$ concentration was increased, indicative of the adoption of $\mathrm{A}-\mathrm{Z}$ junctions in these RNAs (Fig. 2b). Measuring CD on stem-loops as in h43 also resulted in a decreased magnitude compared to measurement with only stems, because the loop restricts the conformationally accessible space. We verified this effect by comparing the CD curves for the AluSx1Jo duplex (Fig. 2b) and an engineered stem-loop version (Supplementary Fig. 3). Z-RNA adoption by h43 and AluSx1Jo was further supported by our negative control using $\mathrm{Za}_{\text {Tyr177Ala }}$, which showed again an increase in the molar ellipticity at $266 \mathrm{~nm}$ and an entirely different behavior over the course of the titration (Fig. $2 c$ and Supplemental Fig. S2).

To parametrize the extent of Z-RNA formation in AluSx1Jo and h43, we derived a Z-conformation score from the CD spectra. Specifically, we calculated the extent of Z-RNA formation (' $E_{Z}$ ') as the growth in molar ellipticity at 285 and $295 \mathrm{~nm}$ and decrease in molar ellipticity at $266 \mathrm{~nm}$ of the fully saturated RNA, normalized to the molar ellipticity at $266 \mathrm{~nm}$ of the free form (calculated using Eq. 1 in "Methods" section). When the RNA is fully converted to a Z-conformation, as with $(\mathrm{CpG})_{3}$ and $(\mathrm{CpG})_{6}, E_{Z} \sim$ 1 (Fig. 2d). Conversely, if the RNA remains in the A-form, $E_{Z} \sim 0$ (for a $\left((\mathrm{ApU})_{6}, \mathrm{G}_{10} \mathrm{C}_{10}\right.$ duplex, as well as for cUUCGg and cGAAAg hairpins; Fig. 2d). A-Z 1 and A-Z 2 had values of 0.2 and 0.19 , respectively, again, reflecting the fact that these RNAs do not fully adopt the Z-conformation (Fig. 2d). For AluSx1Jo and $\mathrm{h} 43, E_{Z} \sim 0.3$ and $\sim 0.2$, respectively, confirming further that these RNAs are very similar to the control A-Z junctions (Fig. 2d). The smaller changes in the CD spectra detected when using $\mathrm{Za}_{\text {Tyr177Ala }}$ instead of $\mathrm{Za}$ (Fig. 2b, c) resulted in a decrease in the $E_{Z}$ score that was threefold to fourfold larger for AluSx1Jo, h43, A-Z 1, and A-Z 2 than for the $(\mathrm{CpG})_{3}$ control (Fig. 2e, calculating using Eq. 2 in "Methods" section). The $E_{Z}$ score therefore represents a suitable standard for evaluating the extent of Z-RNA formation for any sequence.

$\mathrm{Za}$ saturates the double-stranded region of AluSx1Jo, h43, and other ribosomal hairpins. We tested additional RNA fragments for their propensity to locally adopt a Z-RNA conformation upon addition of $\mathrm{Za}$. Using $\mathrm{CD}$, we characterized the binding of $\mathrm{Za}$ to chemically synthesized fragments corresponding to helices h41, h30, H25, and H66 (large subunit, LSU) from E. coli ribosomes, and h41, h30, and H66 from $H$. sapiens ribosomes, which had all been shown to bind to $\mathrm{Z} \alpha$ in ribosome pull-down experiments ${ }^{37}$. We calculated the $E_{Z}$ score of each tested fragment (Supplementary Figs. 3 and 4a; Supplementary Table 1).

For these RNAs, the fully saturated spectra more closely resembled A-Z 1 and A-Z 2 than they did $(\mathrm{CpG})_{3}$. $E_{Z}$ scores ranged from $\sim 0.1$ to 0.47 (Supplementary Table 1 ), indicating that all tested fragments adopted $\mathrm{A}-\mathrm{Z}$ junctions, but to various extents. Most fragments had $E_{Z}$ values in the 0.1-0.2 range, unless they formed extended duplexes at the high concentrations required by the $\mathrm{CD}$ measurements, as was the case for H66 from $H$. sapiens (0.3) and for h41 from E. coli (0.47), which we monitored by AUC (see next paragraph). These duplexes were nonetheless interesting, as their predicted secondary structure (Supplementary Fig. 4a) suggested that in addition to recognizing YpR steps-of which these fragments had a high concentrationZa may favor regions rich in non-canonical base pairs. In support of that possibility, the $E_{z}$ score correlated well to the number of predicted non-Watson-Crick pairs $(R=0.78)$ and to RNA length $(R=0.75)$ (Supplementary Fig. $4 \mathrm{~b})$.

To determine the stoichiometric ratio of RNA and $\mathrm{Za}$ within a complex, we conducted AUC experiments with $\mathrm{Za}: \mathrm{RNA}$ at a ratio of 6:1. We tested the following fragments: $(\mathrm{CpG})_{3}$, cUUCGg hairpin, h43 (E. coli), H25 (E. coli), H66 (H. sapiens), H66 (E. coli), h41 (H. sapiens and E. coli), and the AluSx1Jo RNA. Specifically, we compared the fitted molecular weights from the AUC measurements with the theoretical molecular weights from increasing stoichiometric ratios of Za:RNA. For each fragment except the negative cUUCGg control (major peak (78\%) at 7.8 $\mathrm{kDa}$, corresponding to unbound $\mathrm{Za}$ ), all potential $\mathrm{Za}$ binding sites according to RNA length were occupied (Supplementary Fig. 5). For example, h43 bound to four $\mathrm{Za}$ molecules (Supplementary Fig. 5), the maximum theoretically possible as its stem comprises 10 base pairs and each Za spans $4-5$ base pairs 25,31 . However, while $96 \%$ of the complexes with h43 had a $4: 1$ ratio of $\mathrm{Za}: \mathrm{RNA}$, the percentage of the saturated complex varied for the other fragments within 54-87\% (Supplementary Fig. 5). In agreement with the $C D$ data, this varying saturation range further suggests variable $\mathrm{A}-\mathrm{Z}$ junction adoption within these RNAs.

We also measured h43 at 1:2 and 1:4 stoichiometric ratios of RNA:Za, which gave molecular weights of $21.3 \mathrm{kDa}$ (at $2: 1$ [RNA]:[Za]) and $27.9 \mathrm{kDa}$ (at 4:1 [RNA]:[Za]), indicating 1:2, and 1:3 h43:Za complexes, respectively (Supplemental Fig. S6). This suggests that while there are four binding sites for $\mathrm{Za}$ on $\mathrm{h} 43$, the second pair of sites are less favorable than the first, as at a 1:4 stoichiometric ratio of h43:Za, there is a $1: 3$ complex and the 1:4 complex only becomes stable by adding additional $\mathrm{Za}$ proteins (at a 1:6 molar ratio of $\mathrm{h} 43: \mathrm{Za}$ ). This result highlights that while $\mathrm{Za}$ is capable of binding a wide variety of RNA sequences, it still retains a sequence specificity that is dependent upon the ability of a particular sequence to adopt the Zconformation.

A-Z junction adoption in AluSx1Jo, H66, h43, and $\mathrm{H} 25$ involves destabilization of adjacent A-RNA. The observations that $\mathrm{Za}$ binds to a variety of Alu and ribosomal sequences and that binding is correlated to the number of non-canonical base pairs raise the question of its sequence specificity. To investigate the context for Z-RNA formation at the nucleotide level upon $\mathrm{Za}$ binding, we used $1 \mathrm{D}{ }^{1} \mathrm{H}-\mathrm{NMR}$ because signatures of Z-DNA/ RNA formation determined from previous work on $(\mathrm{CpG})_{\mathrm{n}}$ RNA/DNA repeats ${ }^{23,43}$ and B-Z junctions ${ }^{31,32}$ can be used as a reference for A-Z junction formation. Specifically, it was shown that Z-RNA formation within the $(\mathrm{CpG})_{3}$ repeat mostly follows a two-step process. First, one $\mathrm{Za}$ binds to one side of the repeat, which begins to convert the RNA to the Z-form. This event promotes binding of a second $\mathrm{Za}$ molecule, which stabilizes the Z-conformation ${ }^{23,43-45}$. The conversion from the A-form to the Z-form in $(\mathrm{CpG})_{3}$ DNA/RNA causes the imino proton of the guanine base within $\mathrm{CpG}$ repeats contacted by $\mathrm{Za}$ to experience slow exchange between the chemical shift positions of the A- and Z-forms ${ }^{23,43}$. For B-Z DNA junctions, on the other hand, the 

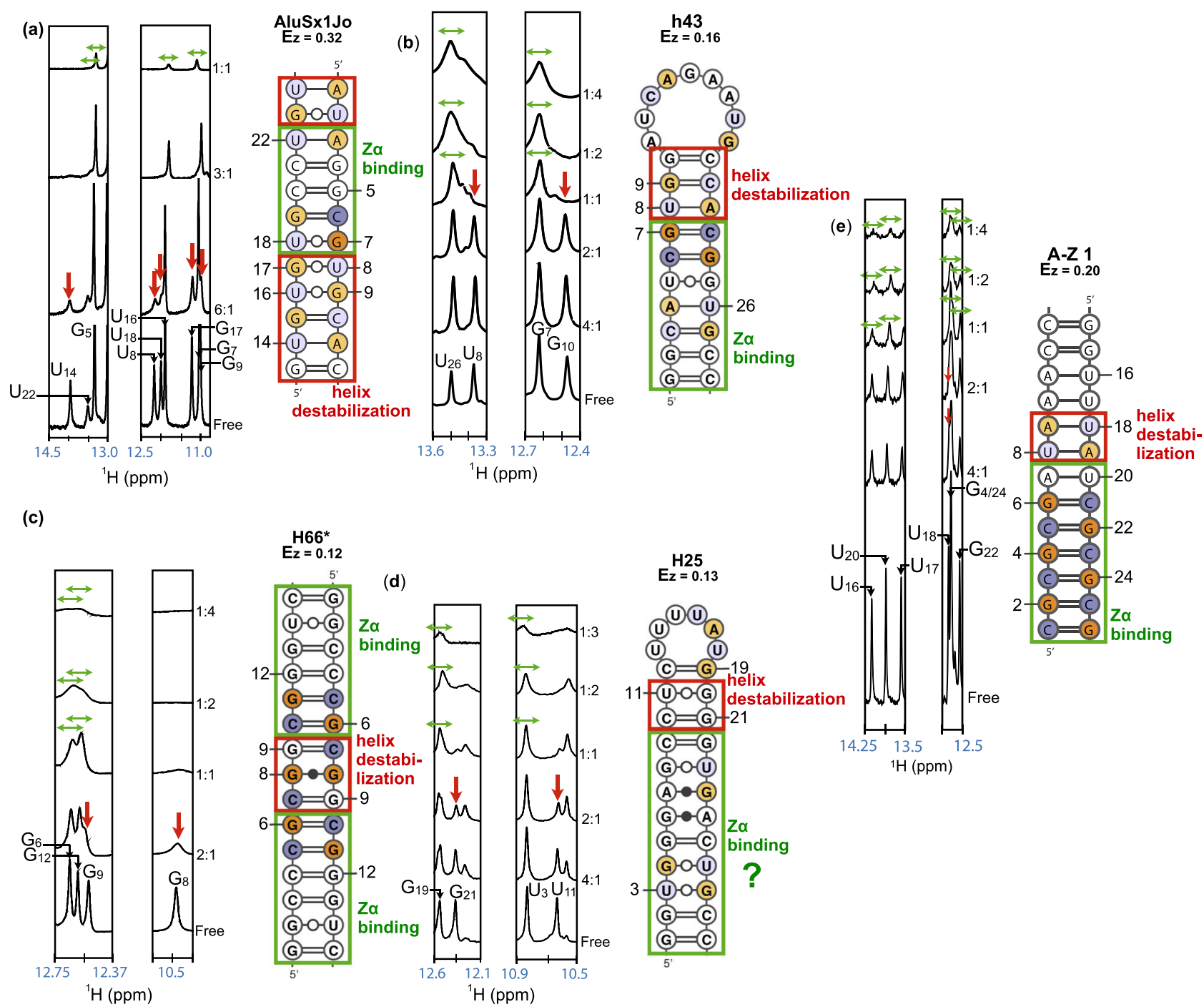

Fig. 3 Pinpointing $\mathrm{Z} \alpha$ binding sites and helix destabilization within various RNA sequence contexts. ${ }^{1} \mathrm{H}-1 \mathrm{D}$ spectra of the following fragments: a AluSx $1 \mathrm{Jo}$, b h43 from E. coli, c H66* (extended duplex) from H. sapiens, d H25 from H. sapiens, e A-Z 1, at decreasing RNA:Z $\alpha$ ratios (right-hand side of the spectra slices). Peak disappearance (vertical red arrows) at low concentrations of $Z \alpha$ (below 1:1) caused by destabilization of the $A$-form helix required for $A-Z$ junction formation is shown. Further line broadening at higher stoichiometric ratios of Z $\alpha$ to RNA (1:1, 1:2, 1:3, 1:4 RNA:Z $\alpha$ ) indicate further binding of Z $\alpha$ proteins and growing complex size (green horizontal arrows). Full imino spectra are shown in Supplementary Fig. 8. For H25, due to the lack of information on the imino protons of $\mathrm{G}_{6}$ and $\mathrm{G}_{24}$, in addition to being unable to determine whether $\mathrm{G} 4$ is destabilized or coalesces with $\mathrm{G} 28$, the exact $Z \alpha$ binding region cannot be confirmed. NMR measurements were performed once as customary, and showed consistency with CD, ITC, and AUC experiments.

adoption of the Z-DNA in the Z-forming sequence is inhibited by neighboring $\mathrm{B}-\mathrm{DNA}^{31,32}$. Therefore, these regions must be destabilized by initial $\mathrm{Za}$ binding before the DNA can adopt the $\mathrm{Z}$-conformation, which causes the imino protons in such regions to disappear into the noise ${ }^{31,32}$. Following this initial destabilization, the $\mathrm{Z}$-forming sequence is shifted to the Z-conformation and can either resemble the $(\mathrm{CpG})_{3}$ case with slow exchange of the syn purines from the B-Z junction, or chemical shift perturbations (CSPs) can be observed instead, depending on the sequence $^{31,32}$.

We followed Z-RNA formation within AluSx1Jo, h43, H66, $\mathrm{H} 25$, and $\mathrm{A}-\mathrm{Z} 1$ with increasing amounts of $\mathrm{Za}$ (imino region of spectra in Fig. 3; $2 \mathrm{D}^{1} \mathrm{H}_{-}{ }^{1} \mathrm{H}$ NOESY assignments and full $1 \mathrm{D}$ imino titrations in Supplementary Figs. S7 and S8). Following the addition of $\mathrm{Za}$ up to a 1:1 ratio, the imino proton resonances of $\mathrm{U}_{14}, \mathrm{U}_{22}, \mathrm{U}_{8}, \mathrm{U}_{18}, \mathrm{G}_{17}$, and $\mathrm{G}_{9}$ of AluSx1Jo disappeared into the noise in a manner similar to what had been observed for the neighboring $\mathrm{B}-\mathrm{DNA}$ in $\mathrm{B}-\mathrm{Z}$ junctions ${ }^{31}$ and the $\mathrm{A}-\mathrm{Z} 1$ control, indicating those base pairs were destabilized (Fig. 3a, e). In addition, the imino protons in the $\mathrm{Z}$-forming regions began to shift towards their bound positions concurrently with the disappearance of the imino protons in the destabilized regions, suggesting that the $\mathrm{Z}$-formation and the destabilization steps were directly coupled. We observed the same behavior for the other three RNA constructs tested (Fig. 3b-d). We confirmed both effects were dependent upon Z-RNA formation as the reduction in the intensity of the same imino peaks when using $Z \alpha_{\text {Tyr177Ala }}$ was stunted relative to the wild-type, and the peaks never fully disappeared into the noise (Supplementary Fig. 9). In addition, the CSPs went in different directions than with wild-type $\mathrm{Za}$ (Supplementary Fig. 9).

At higher stoichiometric ratios of RNA:Za (1:1, 1:2, 1:3, 1:4), we also observed CSPs and line broadening (indicating the increase in complex size) in the base pairs that were not 
destabilized below 1:1 RNA:Za. These results indicated loading of additional $\mathrm{Za}$ proteins onto the different RNAs, in agreement with our $\mathrm{CD}$ and AUC results (Fig. 2 and Supplementary Figs. S2-S5). Plotting of the CSPs onto the secondary structures of the tested RNAs allowed us to determine the $\mathrm{Za}$ binding sites (Fig. 3, green boxes). Similarly to what was observed for B-Z DNA junctions ${ }^{31}$ and $\mathrm{A}-\mathrm{Z} 1, \mathrm{Za}$ binds to specific regions within AluSx1Jo, H66 (extended duplex), and h43, usually having a high concentration of $\mathrm{G}-\mathrm{C}$ base pairs and one or more (YpR) steps. Binding also coincides with destabilization of the adjacent base pairs (Fig. 3). This is consistent with the formation of $\mathrm{A}-\mathrm{Z}$ junctions within these RNAs and is supported by our CD results, which showed only partial Z-formation.

For $\mathrm{H} 25, \mathrm{Za}$ appeared to target the lower portion of the stem which contained only two (YpR) steps and two G.A base pairs (Fig. 3d). However, the exact binding site could not be pinpointed as for the other fragments due to a lack of observable imino proton resonances for the G.A pairs at the temperature used for the titration. In addition, we cannot confirm whether the imino peak of G4 disappears into the noise due to $\mathrm{Za}$-dependent destabilization or whether it simply coalesces with G28 (Supplemental Fig. S8). The observation that the base-paired U27 peak does not disappear supports the latter conclusion, suggesting that the binding site comprises nine base pairs (four Za binding sites) and would be in agreement with our AUC data (Supplementary Fig. S5). We did not observe any slow exchange between the Aand Z-form of any imino peaks in our RNA constructs as was the case for the $(\mathrm{CpG})_{3} \mathrm{RNA}^{23}$, with the exception of U11 and G21 of $\mathrm{H} 25$ (although we could not confirm that these were due to ZRNA formation). This could be for a number of reasons, the most likely being that the formation of Z-RNA in RNAs with some sequence contexts is more dynamic and thus the conformations are exchanging on a faster timescale.

While the observed disappearance of imino peaks could be caused by line broadening due to intermediate exchange, the striking similarity to titrations done on the B-Z DNA junction ${ }^{31}$ suggests that this is not the case. In addition, we did not observe the re-emergence of these peaks at higher concentrations of $\mathrm{Za}$ which we would expect as the complex becomes more stable in the case of intermediate exchange.

Za prefers dsRNA sequences adjacent to less stable helical elements. We noticed the regions being destabilized upon $\mathrm{Za}$ binding usually occurred in regions with many non-canonical base pairs or near a helix end or loop (Fig. 3). Our CD results had revealed that the capping of a helix with a stable cUUCGg tetraloop decreased its $E_{Z}$ score (Supplementary Fig. 3, Supplementary Table 1 ), and that $E_{Z}$ correlated with the number of nonWatson-Crick pairs (Supplementary Fig. 4b). Together, these observations made us inquire whether $\mathrm{Za}$ might be targeting stable dsRNA regions which are adjacent to regions with lower helical stability, as the thermodynamic barrier for Z-RNA adoption may be lower in such contexts.

Comparing the regions on AluSx1Jo and H66 which are bound or destabilized by Za to predicted base-pair stabilities ${ }^{46}$ showed that $\mathrm{Za}$ binds to the region(s) with generally the highest stability (low free energy) and tends to destabilize those with the lowest stabillity (Fig. 4a). The region of h43 which is destabilized by $\mathrm{Za-}$ binding is immediately before h43's nine-nucleotide loop (Fig. 4a), which lends further support to this hypothesis. H25 is an interesting case because the region that $\mathrm{Za}$ appears to bind is relatively unstable (Fig. 4a). However, unlike AluSx1Jo, H66, and h43, H25 lacks a stretch of four or more Watson-Crick pairs and contains very few (YpR) steps. H25 may therefore be a poor Z-adopting RNA according to our NMR measurements, an observation that could not be fully resolved with the resolution of $\mathrm{CD}$ (H25 and H66 both have an $E_{Z}$ score of $\sim 0.1$ ).

Tracking the disappearance of the imino peaks versus $\mathrm{Za}$ concentration revealed that AluSx1Jo, h43, H66, and $\mathrm{H} 25$ are destabilized at different concentrations. Specifically, the concentration of $\mathrm{Za}$ required to reduce the imino peak signals to $90 \%$ of their initial value is about 2.5-fold less for AluSx1Jo than for h43, twofold less than for H66, and eightfold less than for $\mathrm{H} 25$ (Fig. 4b). The concentration of $\mathrm{Za}$ at which the A-form regions are destabilized in an RNA is likely directly related to the thermodynamic barrier of converting an RNA to the Zconformation, as the neighboring A-form regions can interfere with the helical movement of the Z-adopting sequence, as was shown for B-Z DNA junctions ${ }^{32}$. Thus, the AluSx1Jo RNA is the best $\mathrm{Z}$-adopting sequence from our selection, followed by H66, h43, and finally $\mathrm{H} 25$.

Za binds cooperatively to AluSx1Jo and h43 in the $\sim 500 \mathrm{nM}-2$ $\mu M$ range. Having determined that $Z a$ induces novel $A-Z$ junctions in our RNA constructs, we sought to characterize how $\mathrm{Za}$ interacts with such elements. To characterize the binding of $\mathrm{Za}$ to AluSx1Jo and h43, we used ITC and NMR measurements. For AluSx1Jo titration into $\mathrm{Za}$, these experiments showed an initial endothermic binding event up to a stoichiometric ratio of 2:1 of Za:AluSx1Jo, followed by a second exothermic event which continued until saturation (Fig. 5a). The first binding event likely reflected a combination between binding, destabilization of the neighboring A-form regions, and Z-RNA formation (an endothermic cooperative process) at the saturating levels of $\mathrm{Za}$ early in the titration. The second event captured the reshuffling of the populations from the 2:1 to $1: 1 \mathrm{Za}$ :AluSx1Jo complex as the RNA began to saturate Za. This model was supported by NMR measurements of the tumbling times (rotational correlation times, $\tau_{\text {corr }}$, calculated from Eq. 3 and the ratio of R2/R1 as described in "Methods" section) of Za with different AluSx1Jo concentrations. These data indicated that the complex size was maximum at 2:1 Za:AluSx1Jo, with a value of $12.6 \mathrm{~ns}$, and decreased to $10.6 \mathrm{~ns}$ at $1: 1$ and finally $9.2 \mathrm{~ns}$ at $1: 2 \mathrm{Za}$ :AluSx1Jo (Fig. 5b, residue-specific relaxation rates shown in Supplementary Fig. 10). These tumbling times were consistent with a 2:1 $\mathrm{Za}$ : AluSx1Jo complex being formed at a $4: 1$ and 2:1 protein:RNA molar ratio, an intermediate complex between $2: 1$ and $1: 1$ at a $1: 1$ molar ratio of protein:RNA and a 1:1 complex at 1:2 protein: RNA. These results demonstrated cooperative binding, in agreement with the observed line broadening of the RNA imino peaks upon increasing concentrations of Za (Fig. 3). The maximum of two bound Za proteins was confirmed by AUC carried out at a 1:6 molar ratio of AluSx1Jo:Za which showed that the majority of the RNA (85\%) was in a complex of molecular weight $21.3 \mathrm{kDa}$ (Fig. 5c) compared to the theoretical complex size of $22.5 \mathrm{kDa}$.

The ITC profile was best fit to a two-site binding model with a $K_{\mathrm{d}}$ of $1.14 \pm 8.85 \mu \mathrm{M}$ when the ratio of Za:AluSx1Jo is $\leq 2$ and $37.6 \pm 103.8 \mathrm{nM}$ when $\geq 2$ (Table 1 ), although the large fitting error and other ITC parameters attests to a more complex binding behavior. Upon globally fitting NMR CSPs (calculated using Eq. 6 from "Methods" section) for five binding-site residues (His159, Lys170, Glu171, Asn173, and Thr191) from a ${ }^{15} \mathrm{~N}$ HSQC titration of $\mathrm{Za}$ and the AluSx1Jo RNA to a two-site binding model (Fig. 5d, individual per-residue fits shown in Supplementary Fig. 11), we obtained a $K_{\mathrm{d}}$ of $2.04 \pm 1.73 \mu \mathrm{M}$. Together, these two independent measures revealed that the affinity of Za for the AluSx1Jo RNA is in the mid-nanomolar to low-micromolar range. 
(a)

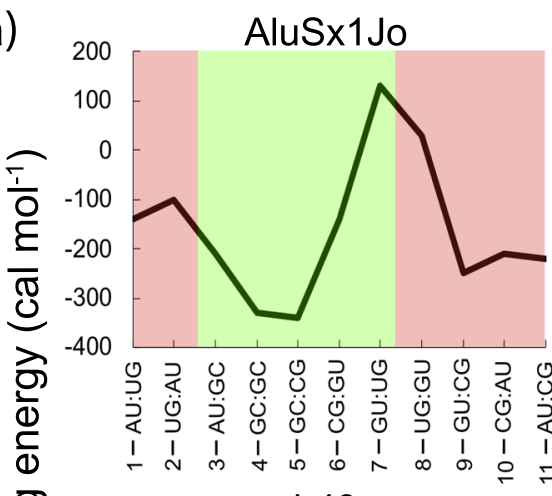

O) -100 h43

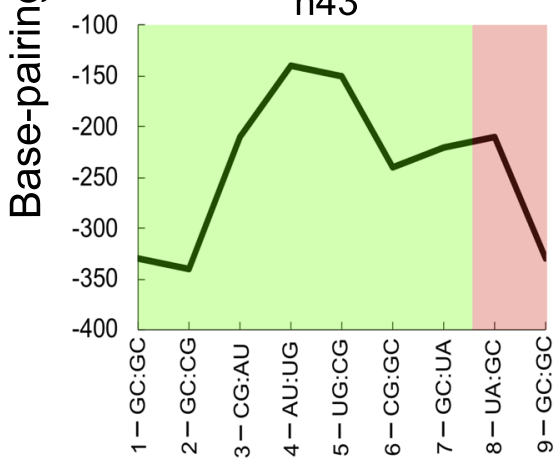

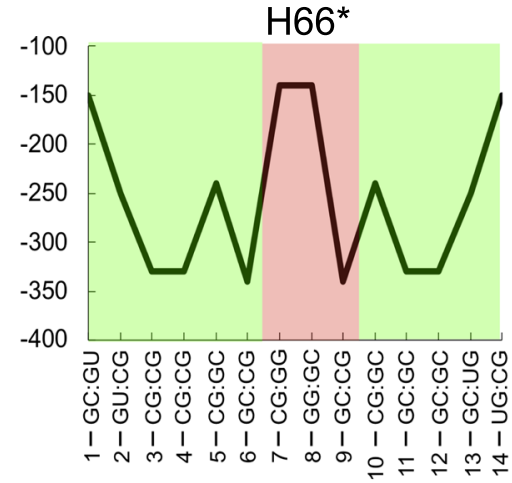

$\mathrm{H} 25$

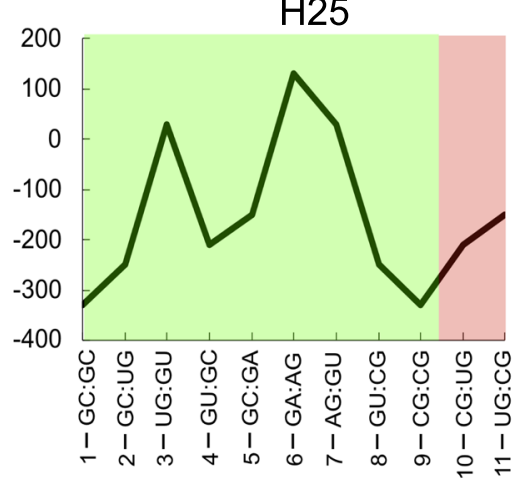

(b)

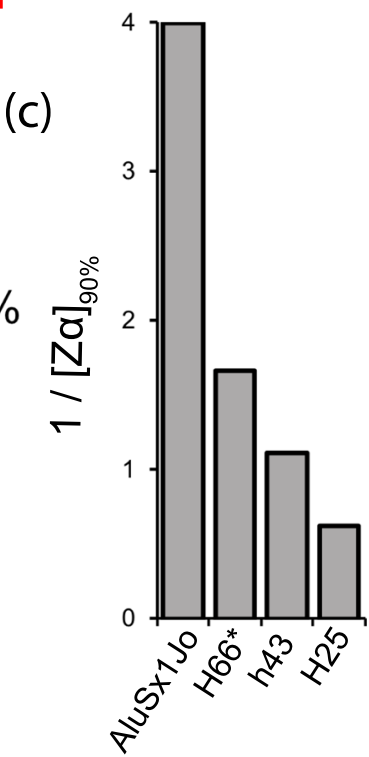

Fig. 4 Destabilization of RNA helices by Z $\alpha$ correlates to base-pair stability. a Regions identified as either being bound (green) or destabilized (red) by $\mathrm{Z} \alpha$ (referring to Fig. 3) are overlayed onto the predicted base-pair free energy (RNAeval ${ }^{46}$ ). b Imino peak height for proton signals in AluSx1Jo, H66* (extended duplex), h43, and H25 RNAs which are destabilized due to Z $\alpha$-binding are shown versus Z $\alpha$ concentration. c The inverse of the Z $\alpha$ concentration at which $90 \%$ of the imino signals disappear into the noise is shown. Peak heights in $\mathbf{b}$ are from 1D NMR titrations (one measurement for each RNA).

ITC measurements of $\mathrm{Za}$ titrated into h43 showed exothermic binding heat with injections up to a Za:RNA molar ratio of 2:1, followed by decreasing binding heat up to a ratio of $4: 1$ (Fig. 5e). This suggested that two $\mathrm{Za}$ molecules were required before h43 could convert to the Z-conformation, with up to four $\mathrm{Za}$ domains bound in the final state, in agreement with the AUC data (Fig. $5 \mathrm{f}$ and Supplemental Fig. S6). Doing the reverse ITC experiment (injecting h43 into $\mathrm{Za}$ ) showed a similar profile of multiple exothermic binding events (Supplemental Fig. S12). The thermogram could be fit to a multisite models, from which $K_{\mathrm{d}}$ values were extrapolated as $538 \pm 314 \mathrm{nM}$ for the first site and $512 \pm$ $1720 \mathrm{nM}$ for the second. Together, our binding analysis revealed that $\mathrm{Za}$ binds specifically and cooperatively to the AluSx1Jo and h43 E.coli RNAs with affinities similar to those of $\mathrm{Za}$ binding to perfect $(\mathrm{CpG})_{\mathrm{n}}$ repeats $\left(K_{\mathrm{d}}\right.$ of $241.5 \pm 1300 \mathrm{nM}$ for $\mathrm{r}(\mathrm{CpG})_{3}$, Fig. $5 \mathrm{~g}$, Table 1 ; and $K_{\mathrm{d}}$ of $9 \mathrm{nM}$ for $(\mathrm{CpG})_{6}$, according to biolayer interferometry measurements in ref. ${ }^{23}$ ), although with more complexity.

Binding of Za to AluSx1Jo resembles binding to $(\mathrm{CpG})_{3}$ but also to a B-Z DNA junction. Previous NMR studies showed that $\mathrm{Za}$ interacts with $(\mathrm{CpG})_{3}$ RNA and DNA repeats differently than B-Z DNA junctions ${ }^{31,32}$. For $(\mathrm{CpG})_{\mathrm{n}}$ repeats, significant CSPs 

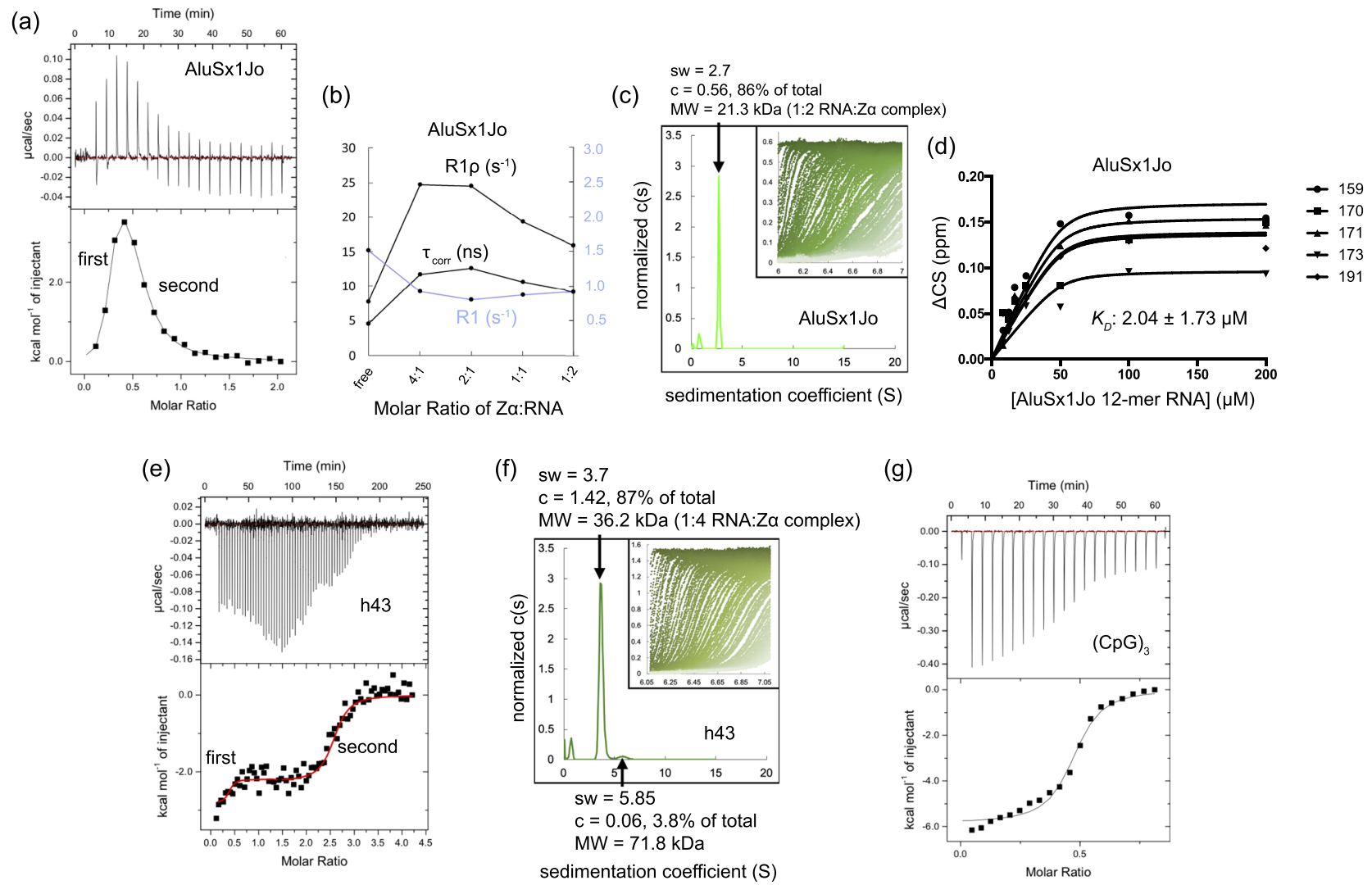

Fig. $5 \mathrm{Z} \alpha$ binds to AluSx1Jo and h43 in the nanomolar to low-micromolar range. a ITC thermogram of AluSx1Jo titrated into Z $\alpha$ and fit to a two-site binding model. b Average (of the corresponding residue-specific values) longitudinal $\left(R_{1}\right)$, and rotating-frame ${ }^{15} \mathrm{~N}$ NMR relaxation rates $\left(R_{1 \rho}\right)$, and the extracted effective overall correlation times $\left(\tau_{\text {corr }}\right)$ are plotted versus the molar ratio of Z $\alpha$ :AluSx1Jo in the experiment (residue-specific $R_{1}, R_{1 \rho}$, and $\tau_{\text {corr }}$ are shown in Supplementary Fig. 9). Measured values are from one set of relaxation rate experiments. c Sedimentation coefficient distribution as obtained from analytical ultracentrifugation (AUC) with a 1:6 molar ratio of AluSz1Jo:Z $\alpha$. The inset shows the raw data from the AUC run with the window position on the $x$-axis and absorbance on the $y$-axis, and individual scans over time going from left to right. $\mathbf{d}$ Global $K_{d}$ fit of chemical shift perturbations (CSPs) of bindingsite residues from the ${ }^{15} \mathrm{~N}-\mathrm{HSQC}$ titration of AluSx1Jo into $\mathrm{Z} \alpha$, assuming a two-site binding model. Values are determined from one ${ }^{15} \mathrm{~N}-\mathrm{HSQC}$ titration. e Isothermal calorimetry (ITC) indicating the multiple $Z \alpha$ domain binding events for $E$. coli h43. f Sedimentation coefficient distribution as obtained from analytical ultracentrifugation (AUC) with a 1:6 molar ratio of $h 43: Z \alpha$. $\mathbf{g}$ ITC thermogram and fit from titrating the (CpG) ${ }_{3}$ RNA into Z $\alpha$. All ITC parameters are given in Table 1. ITC thermograms are representatives of two measurements and AUC data for AluSx1Jo and h43 are determined from one measurement each.

Table 1 Parameters extracted from isothermal titration calorimetry experiments.

\begin{tabular}{|c|c|c|c|c|c|}
\hline Interaction (cell/syringe) & $\boldsymbol{N}$ & $K_{d}(\mathrm{nM})$ & $\Delta H\left(\mathrm{kcal} \mathrm{mol}^{-1}\right)$ & $T \Delta S\left(\mathrm{kcal} \mathrm{mol}^{-1}\right)$ & $\Delta G\left(\mathrm{kcal} \mathrm{mol}^{-1}\right)$ \\
\hline $\mathrm{Z} \alpha /(\mathrm{CpG})_{3}$ & $0.4 \pm 0.0$ & $241.5 \pm 1300.0$ & $-6.0 \pm 0.1$ & 3.0 & -9.0 \\
\hline $\mathrm{Z} \alpha /$ AluSx1Jo & $0.2 \pm 0.0 / 0.3 \pm 0.0$ & $37.6 \pm 103.8 / 1140.3 \pm 8849.6$ & $-0.1 \pm 0.2 / 5.9 \pm 0.6$ & $10.0 / 14.0$ & $-10.1 /-8.1$ \\
\hline
\end{tabular}

$(>0.2 \mathrm{ppm})$ to the backbone residues of $\mathrm{Za}$ were observed for $\beta 1-\alpha 2$ and $\beta 2-$ loop- $\beta 3$ regions of $Z \alpha^{23,32,43}$, which reflect the binding of two Zas and conversion to the Z-conformation. For $\mathrm{B}-\mathrm{Z}$ DNA junctions, $\mathrm{Za}$ experiences less extreme CSPs $(<0.15 \mathrm{ppm})$ and the disappearance of residues $173-177$ due to intermediate exchange, which was proposed to reflect an "initial contact conformation" where $\mathrm{Za}$ binds to the $\mathrm{Z}$-adopting sequence and destabilizes the neighboring B-form regions $s^{32}$.

We employed NMR on ${ }^{15} \mathrm{~N}$-labelled $\mathrm{Za}$ to investigate how similar the binding site of AluSx1Jo on $\mathrm{Za}$ is to that of (CpG)n repeats and to that of a B-Z DNA junction. The CSPs (calculated using Eq. 5 from "Methods" section) were non-linear and coupled with line broadening (Fig. $6 \mathrm{a}$, full ${ }^{15} \mathrm{~N}-\mathrm{HSQC}$ titration shown in Supplementary Fig. 13). These results indicated complex, multisite binding, consistent with our previous ITC, CD, AUC, and NMR results (Figs. 2-5). In addition, there were distinct differences in the peak positions between $2: 1$ and 1:1/1:2 $\mathrm{Za}$ : AluSx1Jo for some of the binding interface residues (Fig. 6b), indicating differences in the backbone conformation of $\mathrm{Za}$ between the state (one versus two $\mathrm{Za}$ bound). This, in combination with our tumbling time analysis (Fig. 5b), suggests that at 2:1 Za:RNA, two Za molecules are bound to AluSx1Jo, which adopts a fully formed A-Z junction. At 1:1/1:2 Za:RNA, however, $\mathrm{Za}$ interacts with AluSx1Jo in the "initial contact conformation", as was seen for B-Z DNA junctions ${ }^{32}$.

The largest CSPs measured from our ${ }^{15} \mathrm{~N}-\mathrm{HSQC}$ titration of AluSx1Jo into Za were mainly concentrated to the Z-RNA binding surface of $\mathrm{Za}$ (amino acids 170-180, 190-194, green 
(a)
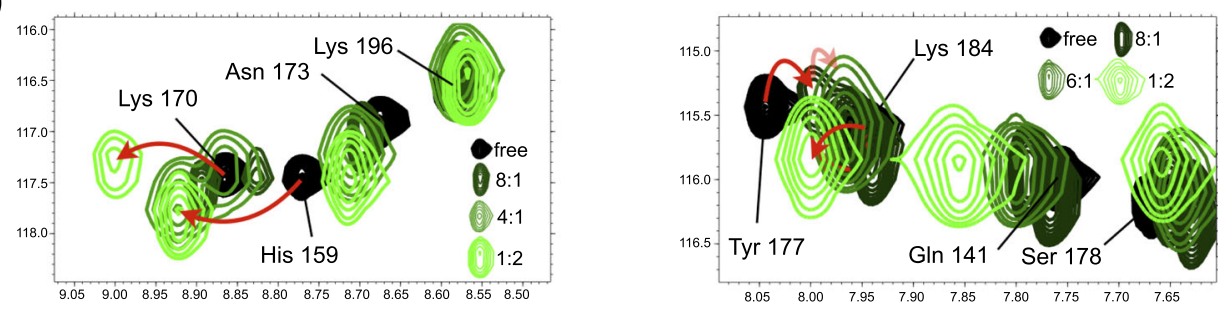

(b)

${ }^{1} \mathrm{H}(\mathrm{ppm})$

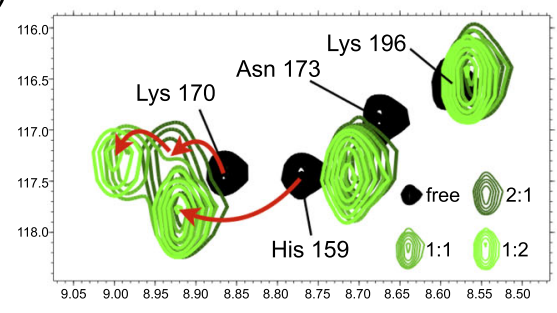

${ }^{1} \mathrm{H}(\mathrm{ppm})$

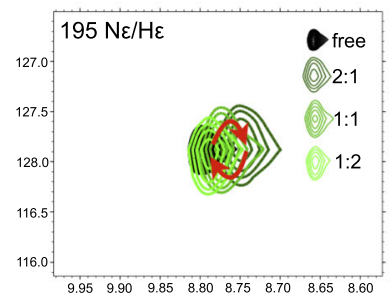

${ }^{1} \mathrm{H}(\mathrm{ppm})$
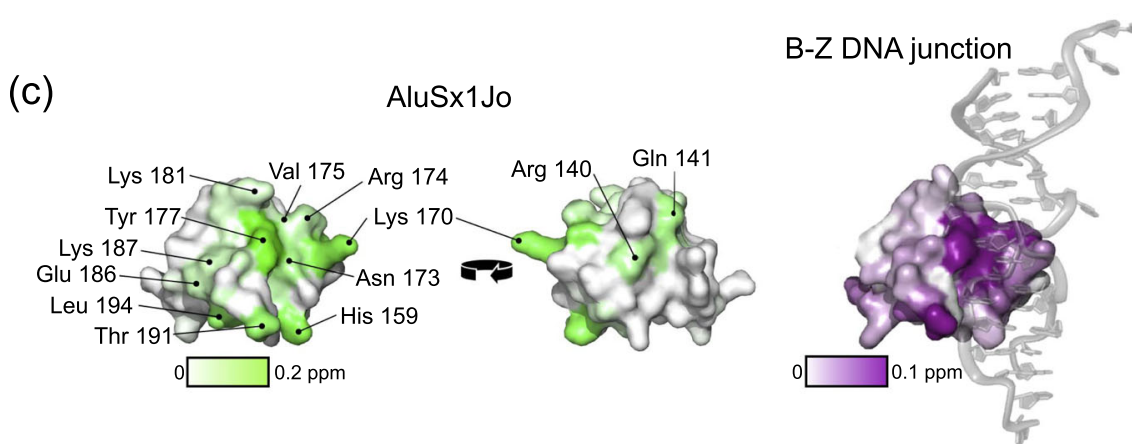

$$
(\mathrm{CpG})_{3} \text { RNA }
$$
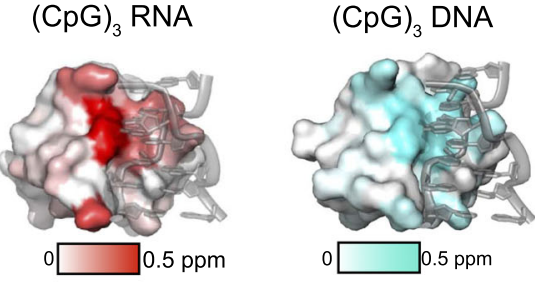

Fig. 6 The binding of $\mathbf{Z} \alpha$ to AluSx1Jo resembles both binding to the (CpG) $\mathbf{3}$ RNA and a B-Z DNA junction. a Representative peaks and their perturbations from the Z $\alpha{ }^{15} \mathrm{~N}-\mathrm{HSQC}$ upon addition of AluSx1Jo. $\mathbf{b}$ Differences in peak positions between free Z $\alpha, 2: 1,1: 1$, and 1:2 Z $\alpha:$ AluSx 1 Jo. Red arrows help show the change in peak positions. c Residues undergoing chemical shift perturbation (CSP) and the CSP magnitudes (Supplementary Fig. $14 \mathrm{a}$ ) from the ${ }^{15} \mathrm{~N}-\mathrm{HSQC}$ titration are indicated on a surface plot of $Z \alpha$ (left, plotted on PDB: $2 \mathrm{GXB}^{25}$ ) and compared to CSPs from titrations of a B-Z DNA junction ${ }^{32}$ (second from left, PDB: $5 Z \cup O^{33}$ ), the $(\mathrm{CpG})_{3} \mathrm{RNA}^{23}$ (second from right, PDB: 2GXB25), and the (CpG) ${ }_{3} \mathrm{DNA}$ (23) (right, PDB: $3 F 21(41)$ ).

color in Fig. 6c, Supplementary Fig. 14). The affected amino acids were similar to those observed when bound to the $(\mathrm{CpG})_{3} \mathrm{RNA}^{23}$ (red, Fig. 6c) and the $(\mathrm{CpG})_{3} \mathrm{DNA}^{23}$ (cyan, Fig. 6c). However, their CSP magnitude was more similar to that observed for amino acids in the complex with a B-Z DNA junction ${ }^{32}$ (purple, Fig. 6c). In contrast to B-Z junctions (where residues 173-177 disappeared), only Tyr 177 experiences intermediate exchange and line broadening beyond detection when bound to AluSx1Jo (Fig. 6a). This was confirmed by Chemical Exchange Saturation Transfer (CEST) measurements at 10:1 Za:RNA, which showed that Tyr177 exhibited exchange on the micro-millisecond timescale with potentially multiple minor states, while Asn173, Arg174, Val175, and Ser178 showed little to no exchange (Supplementary Fig. 15). Hence, $\mathrm{Z} \alpha$ interacts with AluSx1Jo in a manner that appears to have characteristics of both a B-Z DNA junction and the $(\mathrm{CpG})_{3}$ RNA repeat.

Our analysis also revealed significant CSPs for Glu141 and His159. Perturbations in Glu141 were unexpected as the amino acid lies near the back side of $\mathrm{Za}$, adjacent to the binding helix. Glu141 may make specific interactions with A-Z junctions as this residue did not shift when bound to a B-Z DNA junction ${ }^{32}$. Notably, His159 had previously been shown to undergo chemical shift changes upon binding to $(\mathrm{CpG})_{3}$ DNA but not RNA, possibly due to differences in the hydrogen bonding networks ${ }^{23}$. Our observation of a significant CSP for His159, combined with CSPs at residues 190-194 that do not occur when bound to
$\mathrm{d}(\mathrm{CpG})_{3}$, suggests that $\mathrm{Za}$ may invoke a hybrid binding mechanism between Z-DNA and Z-RNA.

The binding of Za to AluSx1Jo is more dynamic than for $(\mathrm{CpG})_{3}$ RNA. Because we did not observe slow exchange between the A-form and Z-form peaks in our RNAs (only CSPs and line broadening), we wondered whether the dynamics of Z-RNA formation might be faster in our constructs relative to the $(\mathrm{CpG})_{3}$ RNA. To answer this question, we acquired Carr-PurcellMeiboom-Gill (CPMG) measurements at 2:1 Za:AluSx1Jo (two $\mathrm{Za}$ residues symmetrically bound around a single Z-step) and compared them to previous CPMG measurements on the $(\mathrm{CpG})_{3}$ DNA and RNA also measured at a 2:1 ratio of Za:RNA ${ }^{23}$. CPMG profiles were globally fit (using Eq. 4 from "Methods" section) to give an exchange rate $\left(k_{\mathrm{ex}}\right)$ between the bound and unbound states of $634 \mathrm{~s}^{-1}$ and major-state population of $96.2 \%$ (Fig. 7 , Supplementary Fig. 16, Supplementary Table 2). Global fits from solely the binding-site helix (residues $169-180,191)$ gave a $k_{\mathrm{ex}}$ and major-state population of $771 \mathrm{~s}^{-1}$ and $95.5 \%$. These exchange rates were similar to what was measured for $\mathrm{Za}$ binding to the $(\mathrm{CpG})_{3}$ DNA ( $k_{\text {ex }}$ of $511 \mathrm{~s}^{-1}$ and $k_{\text {ex }}$ for binding-site residues alone of $762 \mathrm{~s}^{-1}$ ), and were therefore roughly 200 -fold higher than for the $(\mathrm{CpG})_{3} \mathrm{RNA}^{23}$. Thus, Z-RNA formation in our RNA constructs is more dynamic than for the canonical $(\mathrm{CpG})_{3}$ repeat, and this may explain why we did not observe slow 
(a)<smiles>[Mg][Mg][Mg][Mg]</smiles>

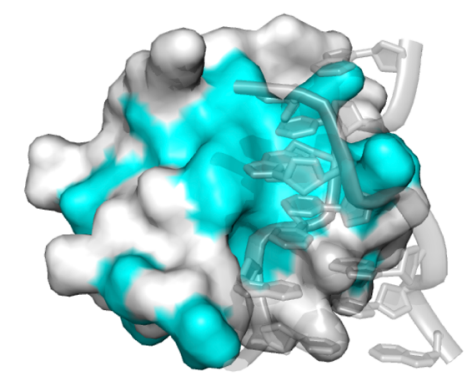

(b)

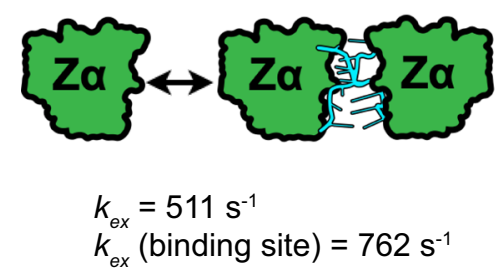

AluSx1Jo
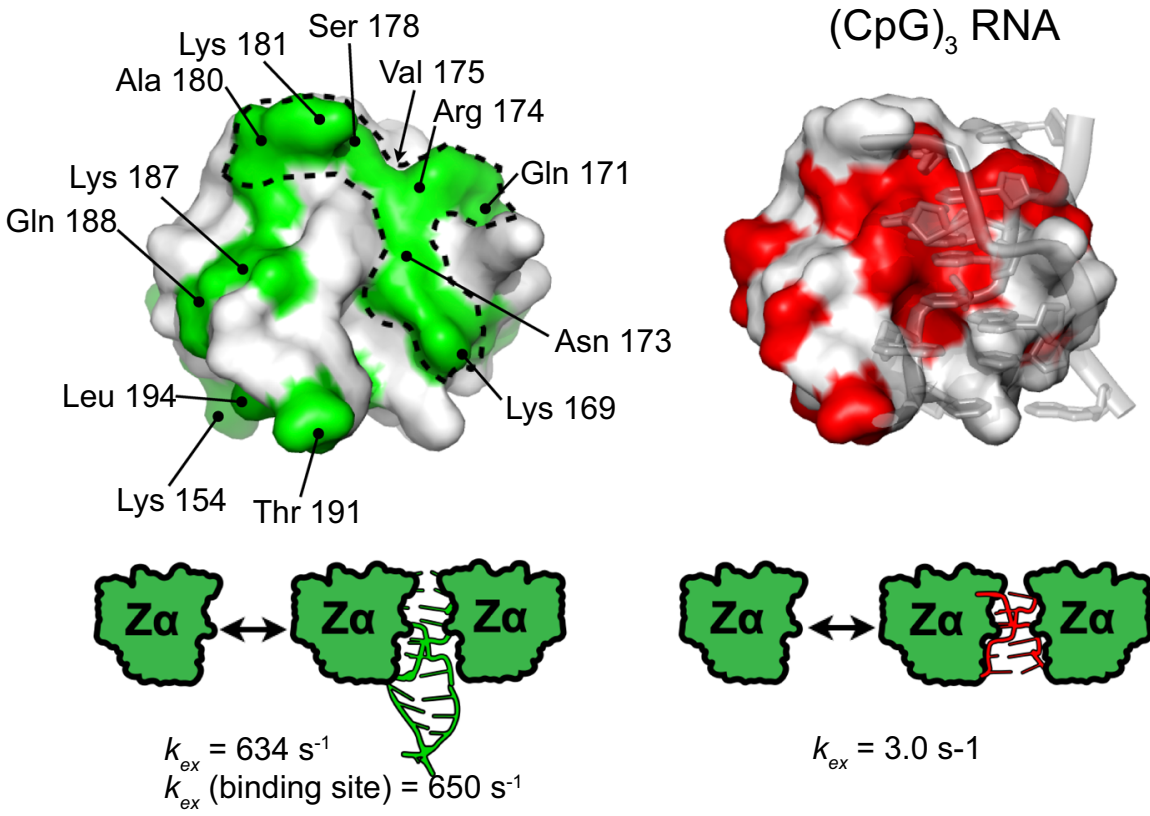

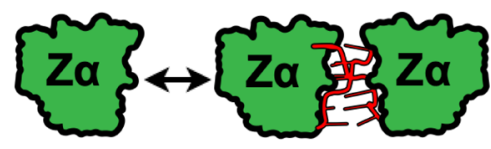

$k_{e x}=3.0 \mathrm{~s}-1$

Fig. 7 The binding of $\mathbf{Z} \boldsymbol{\alpha}$ to AluSx1Jo is more dynamic than to $(\mathbf{C p G})_{\mathbf{3}}$ RNA. a Residues for which CPMG data and exchange rates ( $k_{\mathrm{ex}}$ ) were obtained between the free and the bound complex at 2:1 Z $\alpha$ :RNA are shown on surface plots of Z $\alpha$ bound to $(C p G)_{3}$ DNA (left, PDB: $3 F 21^{47}, k_{\text {ex }}$ rates from ${ }^{23}$ ), to $(\mathrm{CpG})_{3}$ RNA (right, PDB: $2 \mathrm{GXB}^{25}, k_{\text {ex }}$ rates from ${ }^{23}$ ), and for the AluSx1Jo RNA (middle, plotted on PDB: 2GXB25; residue-specific CPMG parameters for the AluSx1Jo are given in Supplementary Table 2 and fits are shown in Supplementary Fig. 16). b Globally fitted $k_{\text {ex }}$ values for Z $\alpha$ binding to, from left to right, $(\mathrm{CpG})_{3} \mathrm{DNA}^{23}$ (all residues or only binding-site residues $k_{\text {ex }}$ values are given), the AluSx 1 Jo RNA (globally fitted CPMG parameters are given in Supplementary Table 3), and $(\mathrm{CpG})_{3} \mathrm{RNA}^{23}$.

exchange between the A- and Z-form peaks in our imino titrations (Fig. 3).

\section{Discussion}

We have characterized various RNA fragments that bind to the $\mathrm{Za}$ domain of ADAR1, even though they do not exclusively comprise $\mathrm{CpG}$ repeats. We have found that these RNAs likely adopt A-Z junctions, evidenced by the similarity of our imino titrations with $Z a$ to those observed for B-Z DNA junctions ${ }^{31,32}$. NMR characterization of the binding of $Z a$ to AluSx1Jo suggests that the mechanism for $\mathrm{A}-\mathrm{Z}$ junction formation upon $\mathrm{Za}$ binding lies somewhere between that of binding to the canonical $(\mathrm{CpG})_{3}$ RNA and that of B-Z junction formation. In addition, our NMR results suggest that the initial interaction of $\mathrm{Za}$ with such RNAs involves the proposed "initial contact formation" 31,32 where $\mathrm{Za}$ begins to destabilize the neighboring A-form regions, followed by the binding of an additional $\mathrm{Za}$ molecule and adoption of the Zconformation (Fig. 8).

Our findings suggest that a wider variety of sequence contexts than previously assumed are able to adopt a Z-conformation, as had been shown for Z-DNA ${ }^{47}$. This observation is in line with the adoption of Z-RNA-like steps by other sequences than $\mathrm{CpG}$ within a large variety of non-coding RNA ${ }^{30}$. This work also offers experimental evidence to support previous proposals that sequences, such as UpG adopt a Z-RNA conformation ${ }^{36}$. Whether the Z-RNA structures adopted by these diverse sequences are similar or represent various types of Z-conformations (as proposed from FRET measurements for $\mathrm{CpG}$ repeats ${ }^{48}$ ) will require structural determination of these complexes.

Even though the nucleotide sequences supporting A-Z junction arrangements are diverse, Z-RNA formation is still subject to a degree of specificity. We observed that $\mathrm{Za}$ targets specific regions with dsRNA that are adjacent to regions which are predicted to be less thermodynamically stable (Figs. 3-4, 8). It has been shown that B-DNA next to a Z-forming sequence in B-Z junctions can present a significant thermodynamic barrier for Z-DNA formation $^{31,32}$. It follows from our analysis that the stability of A-form regions adjacent to a Z-forming sequence in RNA would pose a similar barrier, and that $\mathrm{Za}$ may favor binding to regions which can be converted to the Z-conformation more easily (dsRNA regions adjacent to regions with low stability). The sequence of the Z-adopting region is likely also important, as for $\mathrm{Za}$ converting B- to Z-DNA ${ }^{49}$. The number of hydrogen bonds at the protein-DNA interface is maximal for CpG but minimal for $\mathrm{TpA}^{29}$. We similarly notice in our study that Alu adopts the Zform at a lower protein concentration than H66 (extended duplex $)>\mathrm{h} 43>\mathrm{H} 25$. From this analysis we conclude that $(\mathrm{CpG})_{\mathrm{n}}$ sequences are better $\mathrm{Z}$-adopting sequences compared to other combinations, but that Gs in any configuration at the binding site (i.e., within $\mathrm{UpG}, \mathrm{ApG}$ or $\mathrm{GpG}$ ) tend to be preferred. Therefore, sequence specificity is likely driven by both the Z-forming propensity of the binding site and the stability of the adjacent regions (Fig. 8). We attempted to correlate the calculated $E_{Z}$ scores to other factors in our tested RNA fragments, such as the number and identity of dinucleotide steps within the RNA. However, the only significant correlations to come out of this analysis were to RNA length and the number of non-canonical base pairs. This highlights the complexity in the factors which contribute to the ability of a particular RNA to adopt the Z-conformation, of which our simple analysis was unable to uncover.

This work supports the hypothesis that Z-RNA formation is a general feature of RNA. We know that Z-DNA conformations are readily adopted during replication and transcription due to 


\section{Za target}

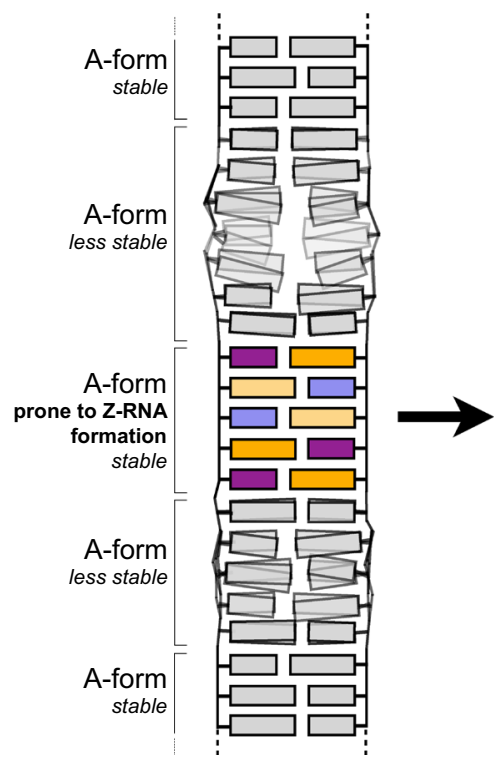

Initial Contact Conformation

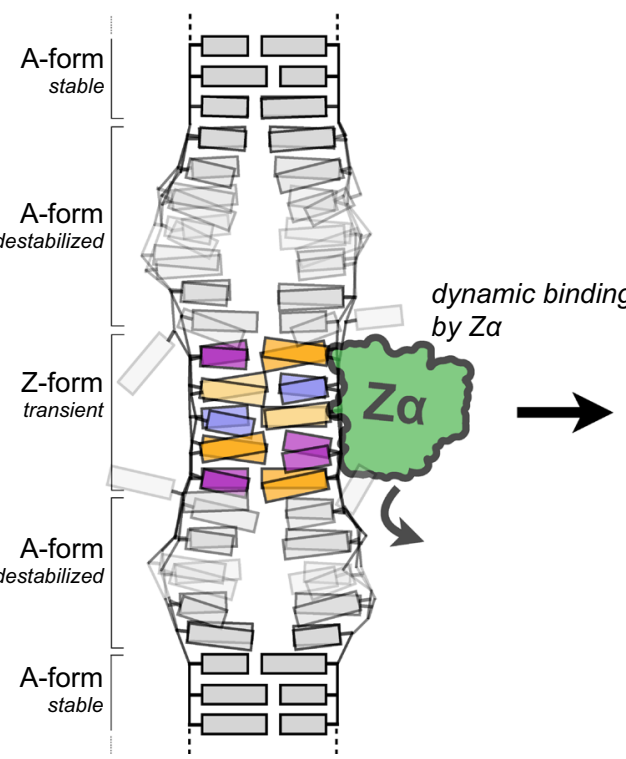

A-Z Junction

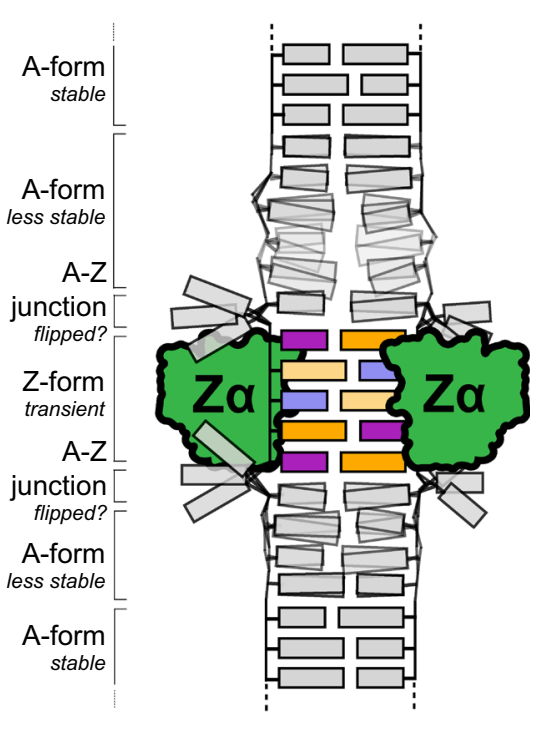

Fig. 8 Model of the sequence specificity of $\mathbf{Z} \boldsymbol{\alpha}$. Cartoon model depicting the proposed sequence specificity of Z $\alpha$. A Z-RNA-prone region of dsRNA is flanked by regions of less stable A-form RNA (left). First, Z $\alpha$ dynamically interacts with the Z-prone sequence (usually comprising YpR steps and nonWatson-Crick pairs) in the initial contact conformation, which begins to convert the region to the Z-conformation, while also destabilizing the neighboring A-form regions (middle). This promotes the binding of another $Z \alpha$ molecule which then stabilizes the Z-conformation and converts the RNA into an A-Z junction (right), which may contain flipped out base pairs as has been seen for B-Z junctions ${ }^{34}$.

unwinding of the two DNA strands ${ }^{50}$. So we could expect Z-RNA conformation to take place upon the many folding/unfolding events associated with the life of an RNA. Many crystal structures of non-coding RNAs reveal Z-RNA-like steps ${ }^{30}$, suggesting they participate in non-standard RNA structure and dynamic events. Our NMR data indicate that Z-RNA formation within the ribosomal and Alu stems is more dynamic than within duplexes made exclusively of $\mathrm{CpG}$ repeats. A dynamic binding of $\mathrm{Za}$ could be a desirable feature for ADAR1, as being bound to only certain RNAs for an extended period of time would likely not be conducive to editing $>10,000$ sites within cellular RNAs.

If Z-RNA formation was a broad mechanism for subtle regulation of RNA expression and/or folding, it would certainly make sense that its sequence requirements would be somewhat loose. A loose RNA sequence requirement for Z-RNA formation would not be paradoxical to recognition by $\mathrm{Za}$ if the sequence requirements for the recognition process were also loose. In fact, double-stranded RNA binding domains from ADAR2 and other proteins display somewhat relaxed sequence requirements ${ }^{51}$. Loose sequence requirements for $\mathrm{Za}$ recognition may actually represent another illustration of the inherent "messy" nature of biology that would be at play during A-to-I editing ${ }^{52}$.

Widespread Z-RNA formation would influence the editing activity of ADAR1, which in turn would affect the proportion of edited versus unedited double-stranded RNA. This mechanism could participate in helping the cell to modulate the innate immune IFN response ${ }^{4}$. Our demonstration that $\mathrm{Za}$ binds to non-CpG repeats at sites rich in non-Watson-Crick pairs and regions of lower stability is in agreement with earlier proposals that $\mathrm{ADAR}$ enzymes recognize their substrates in two separate events ${ }^{39,40}$. As such, the role of $\mathrm{Za}$ could be to attract or deliver ADAR1 to a particular structure adjacent to sites that would thus eventually be recognized by the double-stranded RNA binding domains and the deaminase domain of ADAR1. Za could increase the lifetime of ADAR1 on RNAs that already have been significantly edited, through binding to or near the mismatches produced by A-to-I editing.

Whether $\mathrm{Za}$ binds to ribosomal stem-loops in vivo remains unclear. It is possible that results from the pull-down assays were biased towards ribosomal RNA sequences, as they are most abundant in RNA extracts ${ }^{37}$. On the other hand, $\mathrm{Za}$ binding to ribosomal RNA could be relevant to ribosome assembly processes $^{37,53}$, or to the fate of ribosomes in the stress granules, where ADAR1 and other Z-binding proteins are also located ${ }^{54,55}$. Studying Z-RNA formation in rRNA stem-loops helped us nonetheless with characterizing $\mathrm{Za}$ binding to non-CpG repeat sequences and to identify similar regions in Alu elements.

Overall, pinpointing Z-RNA formation, occurrence, stability, and recognition by other macromolecules is crucial to getting the full picture of gene regulation. Once we better understand the structural underpinnings of Z-RNA formation, we will be able to determine how widespread such conformations are and what their role is within the cell.

\section{Methods}

Plasmid construction, protein purification, and experimental buffers. The $\mathrm{N}$ terminal $\mathrm{Za}$ domain of Homo sapiens ADAR1 in the pet-28a(+) plasmid $(\mathrm{N}-$ terminal 6x His-tag and thrombin cleavage site between His-tag and the $\mathrm{Za}$ sequence) was a gift from Drs. Peter Dröge and Alekos Athanasiadis. Za was expressed and purified similarly to ${ }^{25,56}$. Briefly, the plasmid was transformed and expresed in BL21(DE3) E. coli. The cultures were grown in Luria Broth and induced with $1 \mathrm{M} \mathrm{IPTG}$ at an $\mathrm{OD}_{600}$ of 0.6 and allowed to express $\mathrm{Za}$ for $4 \mathrm{~h}$ at $37^{\circ} \mathrm{C}$, then centrifuged to collect the cell pellets. Pellets were resuspended in lysis buffer (50 mM Tris- $\mathrm{HCl}$ ( $\mathrm{pH} 8.0$ ), $300 \mathrm{mM} \mathrm{NaCl}, 10 \mathrm{mM}$ Imidazole, $5 \mathrm{mM} \beta$ Mercaptoethanol (BME)) and sonicated. Lysate was centrifuged and the supernatant was applied to a His-trap column, washed with $40 \mathrm{~mL}$ of lysis buffer, $80 \mathrm{~mL}$ of wash buffer ( $50 \mathrm{mM}$ Tris- $\mathrm{HCl}$ ( $\mathrm{pH} 8.0$ ), $1 \mathrm{M} \mathrm{NaCl}, 10 \mathrm{mM}$ Imidazole, $5 \mathrm{mM}$ BME), and eluted in $20 \mathrm{~mL}$ of elution buffer (50 mM Tris- $\mathrm{HCl}(\mathrm{pH} 8.0), 300 \mathrm{mM}$ $\mathrm{NaCl}, 500 \mathrm{mM}$ Imidazole, $1 \mathrm{mM} \mathrm{BME}$ ). The eluted fraction was then dialyzed into thrombin buffer ( $5 \mathrm{mM}$ Tris- $\mathrm{HCl}(\mathrm{pH} 8.0), 37.5 \mathrm{mM} \mathrm{NaCl}, 62.5 \mathrm{mM} \mathrm{CaCl}$, $0.5 \mathrm{mM}$ DTT), and incubated with bovine thrombin (Millipore-Sigma, Burlington, MA) at room temperature overnight. The resulting samples were then reapplied to a His-trap column and the flow-through was collected. The flow-throughs were 
then concentrated to $\sim 2 \mathrm{~mL}$ and applied to a Superdex 75 Gel Filtration Column $(120 \mathrm{~mL}, \mathrm{GE}$ Healthcare) and peak corresponding to pure $\mathrm{Za}$ was collected and concentrated using an Amicon $3 \mathrm{kDa}$ cutoff centrifugal filter (Millipore-Sigma, Burlington, MA). $\mathrm{Za}_{\text {Tyr177Ala }}$ mutant was ordered from GenScript and prepared the same way as $\mathrm{Za}$. Proteins were dialyzed into $20 \mathrm{mM}$ potassium phosphate ( $\mathrm{pH} 6.4$ ), $25 \mathrm{mM} \mathrm{NaCl}, 0.5 \mathrm{mM}$ EDTA for NMR titrations $(75 \mathrm{mM} \mathrm{NaCl}$ for Z $\mathrm{Z}-\mathrm{Z} \beta$, see below), and for ITC, proteins were dialyzed in the same beaker with the RNA (to match buffer conditions) in $20 \mathrm{mM}$ potassium phosphate (pH 7.0), $25 \mathrm{mM} \mathrm{NaCl}$, $0.5 \mathrm{mM}$ EDTA, and $1 \mathrm{mM}$ DTT. Proteins were concentrated using Amicon $3 \mathrm{kDa}$ cutoff centrifugal filters. For CD and AUC, proteins were diluted into respective buffers from concentrated stocks. The buffers were as follows: $20 \mathrm{mM}$ potassium phosphate (pH 6.4), $25 \mathrm{mM} \mathrm{NaCl}, 0.5 \mathrm{mM}$ EDTA, $1 \mathrm{mM}$ DTT for CD, and $20 \mathrm{mM}$ potassium phosphate ( $\mathrm{pH} 7.0), 25 \mathrm{mM} \mathrm{NaCl}, 0.5 \mathrm{mM}$ EDTA, and $1 \mathrm{mM}$ DTT for AUC.

RNA preparation. RNA constructs were purchased from Horizon Discovery (Boulder, CO) with HPLC purification. RNAs for NMR titrations were dialyzed into $20 \mathrm{mM}$ potassium phosphate ( $\mathrm{pH}$ 6.4), $25 \mathrm{mM} \mathrm{NaCl}, 0.5 \mathrm{mM}$ EDTA, and concentrated to $300 \mu \mathrm{L}$ using Amicon $3 \mathrm{kDa}$ cutoff centrifugal filters followed by heat denaturing at $95^{\circ} \mathrm{C}$ for $1 \mathrm{~min}$ and rapid cooling on ice. $\mathrm{D}_{2} \mathrm{O}$ was added to $5 \%$ prior to NMR measurements. The RNAs for $\mathrm{CD}$ and AUC were resuspended at $1 \mathrm{mM}$ in RNAse free $\mathrm{ddH}_{2} \mathrm{O}$ and diluted to the concentrations indicated for the experiments. For ITC, the RNAs were dialyzed in the same beaker as the proteins in order to match the buffer conditions and concentrated afterwards using $3 \mathrm{kDa}$ cutoff centrifugal filters.

Circular dichroism. All CD measurements were collected in 1-nm steps from 320 to $220 \mathrm{~nm}$ using a JASCO J-815 CD spectrometer (run using Spectra Manager version 2 (JASCO)) in a $0.1 \mathrm{~cm}$ quartz cuvette in $20 \mathrm{mM}$ potassium phosphate $(\mathrm{pH}$ 6.4), $25 \mathrm{mM} \mathrm{NaCl}, 0.5 \mathrm{mM}$ EDTA, and $1 \mathrm{mM}$ DTT at $25^{\circ} \mathrm{C}$. Two scans were acquired and averaged. RNAs were heat denatured at $95^{\circ} \mathrm{C}$ for $1 \mathrm{~min}$ followed by rapid cooling on ice and titration samples were prepared by incubating $50 \mu \mathrm{M}$ of the RNA constructs with the specified amount of $\mathrm{Za}$ or $\mathrm{Za}_{\mathrm{Tyr177Ala}}$ at $42^{\circ} \mathrm{C}$ for $30 \mathrm{~min}$ and then bringing the samples down to $25^{\circ} \mathrm{C}$ over a period of $20 \mathrm{~min}$. Control experiments were run to ensure that the absorbance of $\mathrm{Za}$ and $\mathrm{Za}_{\mathrm{Tyr} 177 \mathrm{Ala}}$ alone at the same concentrations was minimal in the $250-320 \mathrm{~nm}$ range (the range which reports on RNA secondary structure) (Supplementary Fig. 2). This indicated that changes in the CD spectra were due to conformational changes in the nucleic acid and not from the superposition of the RNA and Za spectra. We tested our RNAs with $6 \mathrm{M}$ sodium perchlorate which was shown to fully induce the Z-conformation in the $(\mathrm{CpG})_{\mathrm{n}} \mathrm{RNAs}^{57}$.

We refer to either the RNA:Protein or the Protein:RNA ratio, with the first molecule mentioned being the one that is being titrated into, for CD, ITC, and NMR measurements.

Extent of Z-formation calculation. To experimentally quantify the extent of Zconformation present in an RNA construct, we introduced a Z-conformation score derived from $C D$ spectra $\left(E_{Z}\right) . E_{Z}$ is based on the $C D$ intensities at wavelengths 285 and $295 \mathrm{~nm}$ (Int ${ }^{285}$ and Int ${ }^{295}$ ), both of which have been shown to be characteristic

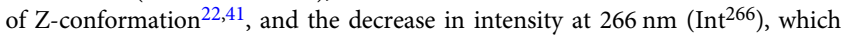
reports on the reduction of the A-form. We assumed that the growth of the intensities at 285 and $295 \mathrm{~nm}$ and decrease at $266 \mathrm{~nm}$ are proportional to the presence of Z-conformation with an offset accounting for intensities measured when no Z-conformation is present. We calibrated the following equation from $\mathrm{CD}$ intensities measured from $(\mathrm{CpG})_{3}$, where the intensities reach plateaus at $100 \% \mathrm{Z}$ conformation:

$$
E_{Z}=\left(1.800 \times \text { decay }^{266}+0.718 \times \text { growth }^{285}+1.109 \times \text { growth }^{295}\right) / 3
$$

where

$$
\begin{gathered}
\text { decay }^{266}=\left(\operatorname{Int}_{\text {free }}^{266}-\operatorname{Int}_{\text {bound }}^{266}\right) / \operatorname{Int}_{\text {free }}^{266} \\
\text { growth }^{285}=\left(\operatorname{Int}_{\text {bound }}^{285}-\operatorname{Int}_{\text {free }}^{285}\right) / \operatorname{Int}_{\text {free }}^{266} \\
\text { growth }^{295}=\left(\operatorname{Int}_{\text {bound }}^{295}-\operatorname{Int}_{\text {free }}^{295}\right) / \operatorname{Int}_{\text {free }}^{266}
\end{gathered}
$$

and the prefactors were chosen so that the $E_{Z}$ score of the $(\mathrm{CpG})_{3}$ RNA would be equal to one.

$E_{Z}$ ideally takes values between 0 (no Z-conformation) and 1 (each nucleotide $100 \%$ in $Z$-conformation). Values between 0 and 1 indicate that the molecule is partially in Z-conformation. This may arise from different contributions from the various nucleotides such that a specific $E_{z}$ score can be achieved by different $\mathrm{Z}$ patterns. For example, if only a subset of the nucleotides adopts Z-conformation at $100 \%, E_{Z}$ will be lower than 1 .

An error of 0.1 was determined to be appropriate for the calculated $E_{Z}$ scores by taking into account the difference between the $(\mathrm{CpG})_{3}$ and $(\mathrm{CpG})_{6}$ RNAs (which theoretically both have an $E_{Z}$ score of 1) and the difference in the $E_{Z}$ score between repeat measurements on h43 E.coli.
The fractional decrease in the $E_{Z}$ score (Fig. 2e) was calculated by the following equation:

$$
\text { Fractional decrease in the } E_{Z} \text { score }=\left(E_{Z Z \alpha \text { Tyr177Ala }}-E_{Z Z \alpha W T}\right) / E_{Z Z \alpha W T}
$$

where $E_{Z \text { ZaWT }}$ and $E_{Z \text { ZaTyr177Ala }}$ are the $E_{Z}$ scores determined from the CD measurements with the wild-type $\mathrm{Z} \alpha$ and mutant $\mathrm{Za}$ (Tyr177Ala), respectively.

Our method is based on the assumption that the RNA in question starts off predominantly in the A-form. For other conformations, our approximation would be less rigorous. We consider not only the changes in the molar ellipticities at 285 and $295 \mathrm{~nm}$, but also at $266 \mathrm{~nm}$ because the loss of the A-form peak is directly related to the transition to the Z-conformation. For Z-RNA junctions where only a portion of the RNA adopts the Z-conformation, the growth at 285 and 295 is not as extensive compared to the $(\mathrm{CpG})_{\mathrm{n}}$ repeat (as was the case for A-Z 1 and A-Z 2, Fig. 2), making including the decrease at $266 \mathrm{~nm}$ more important. In addition, a change in the CD spectra, such as the stabilization of the A-form conformation can result in the peak increasing in height and broadening and consequently, increasing the molar ellipticity at 285 and $295 \mathrm{~nm}$, thereby falsely contributing to the $E_{Z}$ score. However, this also means that the $E_{Z}$ score is sensitive to both the switch from the A- to the Z-conformation and also the destabilization of the neighboring A-RNA While the $E_{Z}$ score may be slightly underestimated by negative contribution to the molar ellipticity at $\sim 290 \mathrm{~nm}$ at the higher concentrations of $\mathrm{Za}$ (Supplementary Fig. S2), this contribution is relatively small and is mostly canceled out by the fact that we weigh the $E_{Z}$ score according to the $(\mathrm{CpG})_{3}$ control (which has the same concentration of $\mathrm{Za}$ as the other constructs).

Isothermal titration calorimetry. RNA constructs for ITC and the Za protein were dialyzed overnight into $20 \mathrm{mM}$ potassium phosphate (pH 7.0), $25 \mathrm{mM} \mathrm{NaCl}$, $0.5 \mathrm{mM}$ EDTA, and $1 \mathrm{mM}$ DTT (in the same beaker to match buffers) and concentrated to $\sim 500 \mu \mathrm{M}$ using Amicon $3 \mathrm{kDa}$ cutoff centrifugal filters. Binding heat was measured on a Malvern ITC200 instrument (run using ITC200 version 1.26.1 (Malvern)) at $25^{\circ} \mathrm{C}$ and $750 \mathrm{RPM}$, with $180 \mathrm{~s}$ injection delays and a reference power of $10 \mu \mathrm{cals}^{-1}$. The titrations of $(\mathrm{CpG})_{3}$ into $\mathrm{Za}$ were measured with twenty $2 \mu \mathrm{L}$ injections of $200 \mu \mathrm{M}$ RNA into $50 \mu \mathrm{M}$ of protein. The titration of Za into h43 E. coli was measured with eighty consecutive $0.5 \mu \mathrm{L}$ injections of $1 \mathrm{mM} \mathrm{Za}$ into $50 \mu \mathrm{M}$ of RNA. The titration of h43 E. coli into Za was measured with twenty $2 \mu \mathrm{L}$ injections of $400 \mu \mathrm{M}$ RNA into $20 \mu \mathrm{M}$ of protein. The titration of AluSx1 Jo into Za was measured with twenty $2 \mu \mathrm{L}$ injections of $200 \mu \mathrm{M}$ RNA into $20 \mu \mathrm{M}$ of protein. All ITC thermograms were analyzed and fit using Microcal Analysis version 7 SR4 (Origin); the details of fitting are detailed in ref. ${ }^{58}$.

Analytical ultracentrifugation. For the interactions between $\mathrm{Za}$ and the different RNAs (Extended Data Fig. 5), the concentrations of Za and the RNA tested were 2 and $12 \mu \mathrm{M}$, respectively, corresponding to a 1:6 ratio of RNA:protein, except for $\mathrm{h} 43$ which was measured at three different concentrations of $\mathrm{Za}(4,8$, and $12 \mu \mathrm{M})$. Samples were loaded into a cell composed of standard $12 \mathrm{~mm}$ EPON centerpieces with quartz windows and sedimented at $50,000 \mathrm{RPM}$ at $25^{\circ} \mathrm{C}$ using an XL-I (Beckman Coulter) AUC instrument (run using ProteomeLab version 6.0 (Beckman)). UV absorbance was monitored at $260 \mathrm{~nm}$ for $16 \mathrm{~h}$. Data were analyzed with SEDFIT (Version $14.7 \mathrm{~g}, \mathrm{NIH})^{59}$ using a specific volume which was normalized to the weight-average of RNA and protein ${ }^{60}$. The complex stoichiometry was chosen according to which theoretical weight was the closest to the measured weight. Error in the measured molecular weight by AUC can be caused by deviation of the predicted specific volume or viscosity of the sample from the actual values. In addition, if one of the binding sites is weaker than the others resulting in decreased site occupancy, this may cause a deviation in the observed molecular weight from the predicted complex size.

NMR experiments. All NMR experiments were carried out on Varian 600 and $900 \mathrm{MHz}$ spectrometers (run using VNMRJ version 4.2 Revision A (Agilent)) equipped with $5 \mathrm{~mm}$ triple resonance ${ }^{1} \mathrm{H} /{ }^{13} \mathrm{C} /{ }^{15} \mathrm{~N}$ cold probes with a $\mathrm{Z}$-axis gradient as well as a Bruker $600 \mathrm{MHz}$ spectrometer (run using TopSpin version 7 (Bruker))_equipped with a $5 / 3 \mathrm{~mm}$ triple resonance ${ }^{1} \mathrm{H} /{ }^{13} \mathrm{C} /{ }^{15} \mathrm{~N} /{ }^{19} \mathrm{~F}$ cryoprobe (CP2.1 TCI). $1 \mathrm{D}^{1} \mathrm{H}$ NMR titrations for h43 E. coli, H66 H. sapiens, and H25 E. coli with Za were carried out on the Varian $600 \mathrm{MHz}$ spectrometer, while the titration for the AluSx1Jo RNA was done on the Bruker $600 \mathrm{MHz}$ spectrometer using a W5 scheme for water suppression (RNA concentration was $500 \mu \mathrm{M}$ for all). The number of scans for all titration points was 128 with a relaxation delay of $1.6 \mathrm{~s}$, and the spectral width was $24 \mathrm{ppm} .2 \mathrm{D}{ }^{1} \mathrm{H}_{-}{ }^{1} \mathrm{H}$ NOESY spectra were recorded on the Varian $900 \mathrm{MHz}$ spectrometer for h43 E. coli, the Varian $600 \mathrm{MHz}$ spectrometer for H66 H. sapiens and H25 E. coli, and the Bruker $600 \mathrm{MHz}$ spectrometer for the AluSxiJo RNA (RNA concentration was $1 \mathrm{mM}$ for all). The $2 \mathrm{D}^{1}{ }^{1} \mathrm{H}-{ }^{1} \mathrm{H}$ NOESY recorded for h43 E. coli was acquired with a mixing time of $200 \mathrm{~ms}, 1470 \times 800$ complex points (399 of the points were actually collected following a 50\% NUS sampling scheme generated using the Schedule Generator from the Wagner group: http://gwagner.med.harvard.edu/intranet/hmsIST/gensched_new.html), a $1.3 \mathrm{~s}$ recycle delay, and 32 scans. The spectral widths were $22 \times 22 \mathrm{ppm}$ for both ${ }^{1} \mathrm{H}$ dimensions. The $2 \mathrm{D}^{1} \mathrm{H}^{1} \mathrm{H}$ NOESY recorded for $\mathrm{H} 66 \mathrm{H}$. sapiens was acquired with a mixing time of $320 \mathrm{~ms}, 1386 \times 400$ complex points ( 162 of the points were collected following a $40 \%$ NUS sampling schedule), a 1.3 s recycle delay, and 
32 scans. The spectral widths were $20 \times 20 \mathrm{ppm}$ for both ${ }^{1} \mathrm{H}$ dimensions. The $2 \mathrm{D}$ ${ }^{1} \mathrm{H}-{ }^{1} \mathrm{H}$ NOESY recorded for $\mathrm{H} 25$ E. coli was acquired with a mixing time of $200 \mathrm{~ms}$, $1396 \times 400$ complex points (162 of the points were collected following a $40 \%$ NUS sampling schedule), a 1.3 recycle delay, and 32 scans. The spectral widths were $20 \times 20 \mathrm{ppm}$ for both ${ }^{1} \mathrm{H}$ dimensions. The $2 \mathrm{D}^{1}{ }^{1} \mathrm{H}-{ }^{1} \mathrm{H}$ NOESY recorded for AluSx1Jo was acquired with a mixing time of $300 \mathrm{~ms}, 1024 \times 400$ complex points, a $2 \mathrm{~s}$ recycle delay, and 32 scans. The spectral widths were $24.5 \times 24.5 \mathrm{ppm}$ for both ${ }^{1} \mathrm{H}$ dimensions. 1D spectra from the Bruker spectrometer were processed using TopSpin; all other data were processed using the NmrPipe/NmrDraw/NlinLS package version $10.9^{61}$. All NUS data were reconstructed using the hmsIST software $^{62}$ (a part of NMRPipe). All assignments were done in ccpNmr analysis version 2.4.263.

For the titration of AluSx1Jo into Za, all NMR measurements were carried out on the Varian $900 \mathrm{MHz}$ spectrometer. The ${ }^{15} \mathrm{~N}-\mathrm{HSQC}$ spectra for the titration were measured with $1048\left({ }^{1} \mathrm{H}\right) \times 60\left({ }^{15} \mathrm{~N}\right)$ complex points with a $1.6 \mathrm{~s}$ recycle delay and 32 scans. The spectral widths were $16 \times 35 \mathrm{ppm}$ for the ${ }^{1} \mathrm{H}$ and ${ }^{15} \mathrm{~N}$ dimensions, respectively. The concentration of $\mathrm{Za}$ was $200 \mu \mathrm{M}$. The $\mathrm{R}_{1}$ relaxation experiments were measured with $1048\left({ }^{1} \mathrm{H}\right) \times 64\left({ }^{15} \mathrm{~N}\right)$ complex points, a recycle delay of $2 \mathrm{~s}$, 16 scans, and relaxation delays of $0,100,200,300,400,500,600,700,800,900$, 1000 , and $1200 \mathrm{~ms}$. The spectral widths were $16 \times 35 \mathrm{ppm}$ for the ${ }^{1} \mathrm{H}$ and ${ }^{15} \mathrm{~N}$ dimensions, respectively. The $\mathrm{R}_{1 \rho}$ relaxation experiments were measured with 1048 $\left({ }^{1} \mathrm{H}\right) \times 64\left({ }^{15} \mathrm{~N}\right)$ complex points, a recycle delay of $2 \mathrm{~s}, 32$ scans, and relaxation delays of $0,10,20,30,40,60,80,100,120$, and $160 \mathrm{~ms}$. The spectral widths were $16 \times 35 \mathrm{ppm}$ for the ${ }^{1} \mathrm{H}$ and ${ }^{15} \mathrm{~N}$ dimensions, respectively. During the $\mathrm{R}_{1 \rho}$ relaxation time, a ${ }^{15} \mathrm{~N}$ spin-lock field of $1500-\mathrm{Hz}$ strength was applied. The transverse relaxation rate $R_{2}$ was calculated from $R_{1}$ and $R_{1 \rho}$ using the following equation:

$$
R_{2}=R_{1 \rho}+\left(R_{1 \rho}-R_{1}\right) \times \tan ^{2}(\theta)
$$

where $\theta=\tan ^{-1}\left(2 \pi \Delta \mathrm{v} / \gamma_{\mathrm{N}} B_{1}\right), \Delta \mathrm{v}$ is the resonance offset, $\left|\gamma_{\mathrm{N}} B_{1} / 2 \pi\right|$ is the strength of the spin-lock field $B_{1}$, and $\gamma_{\mathrm{N}}$ is the gyromagnetic ratio of the ${ }^{15} \mathrm{~N}$ spin.

$\tau_{\text {corr }}$ was calculated from the ratio of $R_{2} / R_{1}{ }_{1}^{64}$. The $\tau_{\text {corr }}$ for free $\mathrm{Za}$ was calculated from $R_{1} / R_{1 \rho}$ measurements done with a $500 \mu \mathrm{M} \mathrm{Za}$ sample instead of the $200 \mu \mathrm{M}$ sample used in the titration.

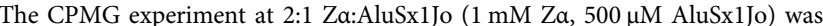
measured on the $600 \mathrm{MHz}$ Bruker spectrometer with $1024\left({ }^{1} \mathrm{H}\right) \times 64\left({ }^{15} \mathrm{~N}\right)$ complex points, a recycle delay of $1.2 \mathrm{~s}, 32$ scans, and $11 v_{\mathrm{CPMG}}$ values $(T=40 \mathrm{~ms})$ ranging from 10 to $1000 \mathrm{~Hz}$. The spectral widths were $16 \times 35 \mathrm{ppm}$ for the ${ }^{1} \mathrm{H}$ and ${ }^{15} \mathrm{~N}$ dimensions, respectively. Dispersion profiles were fit to a two-state fast CPMG exchange model with the following equation:

$$
R_{\text {2eff }}=R_{2 \mathrm{a}}+p_{\mathrm{a}} \times\left(1-p_{\mathrm{a}}\right) \times\left(\Delta \omega^{2}\right) / k_{\mathrm{ex}} \times\left\{1-\left(4 \times v_{\mathrm{CPMG}} / k_{\mathrm{ex}}\right) \times\left(\tanh \left(k_{\mathrm{ex}} / v_{\mathrm{CPMG}} / 4\right)\right)\right\}
$$

where $R_{2 \mathrm{a}}$ and $\mathrm{p}_{\mathrm{a}}$ are the $R_{2}$ relaxation rate and the population of state $\mathrm{A}, \Delta \omega$ is the difference in the chemical shift between states A and $\mathrm{B}, k_{e x}$ is the rate of exchange between states $\mathrm{A}$ and $\mathrm{B}$, and $v_{\mathrm{CPMG}}$ is the effective field strength of the refocusing pulse train.

The ${ }^{15} \mathrm{~N}-\mathrm{CEST}$ experiment at 10:1 Za:AluSx1Jo (1 mM Za, $100 \mu \mathrm{M}$ AluSx1Jo) was measured on the $600 \mathrm{MHz}$ Bruker spectrometer with $\left.1024{ }^{(1} \mathrm{H}\right) \times 64\left({ }^{15} \mathrm{~N}\right)$ complex points, a $1 \mathrm{~s}$ recycle delay, and 16 scans. The spectral widths were $16 \times 35$ ppm for the ${ }^{1} \mathrm{H}$ and ${ }^{15} \mathrm{~N}$ dimensions, respectively. A weak ${ }^{15} \mathrm{~N} B_{1}$ field of $5 \mathrm{~Hz}$ strength was applied during a $400 \mathrm{~ms}$ relaxation time. A total of 66 datasets were acquired corresponding to a chemical shift range of $102-132 \mathrm{ppm}$ with steps of 0.5 $\mathrm{ppm}$. From 115 to $116 \mathrm{ppm}$, the steps were decreased to $0.25 \mathrm{ppm}$ to acquire additional points around Tyr177. In all experiments, ${ }^{1} \mathrm{H}$ decoupling was achieved using a $90_{\mathrm{x}} 240_{\mathrm{y}} 90_{\mathrm{x}}$ composite pulse.

$\boldsymbol{K}_{\boldsymbol{D}}$ fitting of NMR titration points. CSPs from the ${ }^{15} \mathrm{~N}-\mathrm{HSQC}$ titration of AluSx1Jo into ${ }^{15} \mathrm{~N}$-labelled $\mathrm{Za}$ were calculated using the following equation ${ }^{65,66}$.

$$
\mathrm{CSP}=\sqrt{\left(\delta_{\mathrm{H}, \text { free }}-\delta_{\mathrm{H}, \text { bound }}\right)^{2}+0.2\left(\delta_{\mathrm{N}, \text { free }}-\delta_{\mathrm{N}, \text { bound }}\right)^{2}}
$$

where $\delta_{H}$ is the chemical shift of a peak in the ${ }^{1} \mathrm{H}$ dimension, and $\delta_{N}$ is the chemical shift of a peak in the ${ }^{15} \mathrm{~N}$ dimension. The $K_{D}$ was determined by fitting CSPs to the following equation ${ }^{66}$ :

$$
\operatorname{CSP}=\operatorname{CSP}_{\max } \times \frac{\left(K_{D}+[L]+\frac{[P]}{2}\right)-\sqrt{\left(\frac{[P]}{2}\right)^{2}-4 \times[L] \times \frac{[P]}{2}}}{2 \times \frac{[P]}{2}}
$$

Where $[P]$ is the concentration of protein in solution (divided by two because the ligand has two binding sites), $[L]$ is the ligand concentration, and $\operatorname{CSP}_{\max }$ is the maximum CSP measured over the series of titration points.

Comparison of CSPs between AluSx1Jo titration and (CpG) ${ }_{3}$ DNA and RNA For comparison of our measured CSPs from ${ }^{15} \mathrm{~N}-\mathrm{HSQC}$ titrations of $\mathrm{Za}$ with the AluSxiJo RNA and those measured for the $(\mathrm{CpG})_{3}$ DNA and RNA ${ }^{23}$ and the B-Z DNA junction ${ }^{32}$, CSPs were estimated from the published bar graphs showing CSPs vs residue number.
Prediction of base-pair-specific free energy of folding for AluSx1Jo, h43, H66, and H25. The base-pair-specific stability energies for AluSx1Jo, h43, H66, and H25 (Fig. 4) were predicted within RNAeval using default parameters ${ }^{46}$ (last accessed at http://rna.tbi.univie.ac.at on September 10, 2020) and plotted vs. base-pair identity. The regions identified as being bound and destabilized by $\mathrm{Za}$ binding were overlayed over the plots.

Reporting summary. Further information on research design is available in the Nature Research Reporting Summary linked to this article.

\section{Data availability}

The data that support this study are available from the corresponding authors upon reasonable request. The datasets generated during and/or analysed during the current study are available in the Dryad repository, with the identifier https://doi.org/10.5061/ dryad.pvmcrdnk4. The crystal structures used in Figs. 6 and 7 (2GXB, 5ZUO, 3F21) are available from the RCSB. Source data are provided with this paper

Received: 14 October 2020; Accepted: 7 January 2021; Published online: 04 February 2021

\section{References}

1. Wagner, R. W., Smith, J. E., Cooperman, B. S. \& Nishikura, K. A doublestranded RNA unwinding activity introduces structural alterations by means of adenosine to inosine conversions in mammalian cells and Xenopus eggs. Proc. Natl Acad. Sci. USA https://doi.org/10.1073/pnas.86.8.2647 (1989).

2. Nishikura, K. A-to-I editing of coding and non-coding RNAs by ADARs. Nat. Rev. Mol. Cell Biol. https://doi.org/10.1038/nrm.2015.4 (2016).

3. Bass, B. L. \& Weintraub, H. An unwinding activity that covalently modifies its double-stranded RNA substrate. Cell https://doi.org/10.1016/0092-8674(88) 90253-X (1988).

4. Chung, $\mathrm{H}$. et al. Human ADAR1 prevents endogenous RNA from triggering translational shutdown. Cell https://doi.org/10.1016/j.cell.2017.12.038 (2018).

5. Mannion, N. M. et al. The RNA-editing enzyme ADAR1 controls innate immune responses to RNA. Cell Rep. https://doi.org/10.1016/j. celrep.2014.10.041 (2014)

6. Patterson, J. B. \& Samual, S. E. Expression and regulation by interferon of a double-stranded-RNA-specific adenosine deaminase from human cells: evidence for two forms of the deaminase. Mol. Cell. Biol. 15, 5376-5388 (1995).

7. O'Connell, M. A. et al. Cloning of cDNAs encoding mammalian doublestranded RNA-specific adenosine deaminase. Mol. Cell. Biol. https://doi.org/ 10.1128/mcb.15.3.1389 (1995).

8. O'Connell, M. A. \& Keller, W. Purification and properties of double-stranded RNA-specific adenosine deaminase from calf thymus. Proc. Natl Acad. Sci. USA https://doi.org/10.1073/pnas.91.22.10596 (1994).

9. George, C. X. \& Samuel, C. E. Human RNA-specific adenosine deaminase ADAR1 transcripts possess alternative exon 1 structures that initiate from different promoters, one constitutively active and the other interferon inducible. Proc. Natl. Acad. Sci. USA https://doi.org/10.1073/pnas.96.8.4621 (1999).

10. Levanon, K., Eisenberg, E., Rechavi, G. \& Levanon, E. Y. Adenosine-to-inosine RNA editing in Alu repeats in the human genome. EMBO Rep. 6, 831-835 (2005).

11. Levanon, E. Y. et al. Systematic identification of abundant A-to-I editing sites in the human transcriptome. Nat. Biotechnol. 22, 1001-1005 (2004).

12. Athanasiadis, A., Rich, A. \& Maas, S. Widespread A-to-I RNA editing of Alucontaining mRNAs in the human transcriptome. PLOS Biol. https://doi.org/ 10.1371/journal.pbio.0020391 (2004)

13. Cordaux, R. \& Batzer, M. A. The impact of retrotransposons on human genome evolution. Nat. Rev. Genet. 10, 691-703 (2009).

14. Heinrich, M. J. et al. Endogenous double-stranded Alu RNA elements stimulate IFN-responses in relapsing remitting multiple sclerosis. J. Autoimmun. https://doi.org/10.1016/j.jaut.2019.02.003 (2019).

15. Hung, T. et al. The Ro60 autoantigen binds endogenous retroelements and regulates inflammatory gene expression. Science https://doi.org/10.1126/ science.aac7442 (2015).

16. Vlachogiannis, N. I. et al. Increased adenosine-to-inosine RNA editing in rheumatoid arthritis. J. Autoimmun. https://doi.org/10.1016/j. jaut.2019.102329 (2020)

17. Zhao, Y. \& Karijolich, J. Know thyself: RIG-I-like receptor sensing of DNA virus infection. J. Virol. https://doi.org/10.1128/jvi.01085-19 (2019).

18. Zhao, Y., Ye, X., Dunker, W., Song, Y. \& Karijolich, J. RIG-I like receptor sensing of host RNAs facilitates the cell-intrinsic immune response to KSHV infection. Nat. Commun. https://doi.org/10.1038/s41467-018-07314-7 (2018). 
19. Pfaller, C. K., Donohue, R. C., Nersisyan, S., Brodsky, L. \& Cattaneo, R. Extensive editing of cellular and viral double-stranded RNA structures accounts for innate immunity suppression and the proviral activity of ADAR1 p150. PLOS Biol. https://doi.org/10.1371/journal.pbio.2006577 (2018).

20. Herbert, A. et al. The Za domain from human ADAR1 binds to the Z-DNA conformer of many different sequences. Nucleic Acids Res. https://doi.org/ 10.1093/nar/26.15.3486 (1998).

21. Schwartz, T., Rould, M. A., Lowenhaupt, K., Herbert, A. \& Rich, A. Crystal structure of the Zalpha domain of the human editing enzyme ADAR1 bound to left-handed Z-DNA. Science 11, 1841-1845 (1999).

22. Brown, B. A., Lowenhaupt, K., Wilbert, C. M., Hanlon, E. B. \& Rich, A. The $\mathrm{Za}$ domain of the editing enzyme dsRNA adenosine deaminase binds lefthanded Z-RNA as well as Z-DNA. Proc. Natl Acad. Sci. USA https://doi.org/ 10.1073/pnas.240464097 (2000).

23. Lee, A. R. et al. NMR dynamics study reveals the Za domain of human ADAR1 associates with and dissociates from Z-RNA more slowly than ZDNA. ACS Chem. Biol. https://doi.org/10.1021/acschembio.8b00914 (2019).

24. Koeris, M., Funke, L., Shrestha, J., Rich, A. \& Maas, S. Modulation of ADAR1 editing activity by Z-RNA in vitro. Nucleic Acids Res. https://doi.org/10.1093/ nar/gki849 (2005).

25. Placido, D., Brown, B. A., Lowenhaupt, K., Rich, A. \& Athanasiadis, A. A lefthanded RNA double helix bound by the Za domain of the RNA-editing enzyme ADAR1. Structure https://doi.org/10.1016/j.str.2007.03.001 (2007).

26. Kruse, H., Mrazikova, K., D’Ascenzo, L., Sponer, J. \& Auffinger, P. Short but weak: The Z-DNA Lone-Pair $\cdots \pi$ conundrum challenges standard carbon van der waals Radii. Angew. Chemie Int. Ed. https://doi.org/10.1002/anie.202004201 (2020).

27. Herbert, A. Mendelian disease caused by variants affecting recognition of $Z$ DNA and Z-RNA by the Za domain of the double-stranded RNA editing enzyme ADAR. Eur. J. Hum. Genet. 28, 114-117 (2020).

28. Rice, G. I. et al. Mutations in ADAR1 cause Aicardi-Goutières syndrome associated with a type i interferon signature. Nat. Genet. https://doi.org/ 10.1038/ng.2414 (2012).

29. Ha, S. C. et al. The structures of non-CG-repeat Z-DNAs co-crystallized with the Z-DNA-binding domain, hZaADAR1. Nucleic Acids Res. https://doi.org/ 10.1093/nar/gkn976 (2009).

30. D’Ascenzo, L., Leonarski, F., Vicens, Q. \& Auffinger, P. 'Z-DNA like' fragments in RNA: a recurring structural motif with implications for folding, RNA/protein recognition and immune response. Nucleic Acids Res. https:// doi.org/10.1093/nar/gkw388 (2016).

31. Lee, Y. M. et al. NMR investigation on the DNA binding and B-Z transition pathway of the Za domain of human ADAR1. Biophys. Chem. https://doi.org/ 10.1016/j.bpc.2012.12.002 (2013).

32. Lee, Y. M. et al. NMR study on the B-Z junction formation of DNA duplexes induced by Z-DNA binding domain of human ADAR1. J. Am. Chem. Soc. https://doi.org/10.1021/ja211581b (2012).

33. Kim, D. et al. Sequence preference and structural heterogeneity of BZ junctions. Nucleic Acids Res. https://doi.org/10.1093/nar/gky784 (2018).

34. Ha, S. C., Lowenhaupt, K., Rich, A., Kim, Y. G. \& Kyeong, K. K. Crystal structure of a junction between B-DNA and Z-DNA reveals two extruded bases. Nature 437, 1183-1186 https://doi.org/10.1038/nature04088 (2005).

35. Kim, D. et al. Base extrusion is found at helical junctions between right- and left-handed forms of DNA and RNA. Nucleic Acids Res. https://doi.org/ 10.1093/nar/gkp364 (2009).

36. Herbert, A. Z-DNA and Z-RNA in human disease. Commun. Biol. https://doi. org/10.1038/s42003-018-0237-x (2019).

37. Feng, S. et al. Alternate rRNA secondary structures as regulators of translation. Nat. Struct. Mol. Biol. https://doi.org/10.1038/nsmb.1962 (2011).

38. Jiao, $\mathrm{H}$. et al. Z-nucleic-acid sensing triggers ZBP1-dependent necroptosis and inflammation. Nature https://doi.org/10.1038/s41586-020-2129-8 (2020).

39. Lehmann, K. A. \& Bass, B. L. The importance of internal loops within RNA substrates of ADAR1. J. Mol. Biol. https://doi.org/10.1006/jmbi.1999.2914 (1999).

40. Daniel, C., Widmark, A., Rigardt, D. \& Öhman, M. Editing inducer elements increases A-to-I editing efficiency in the mammalian transcriptome. Genome Biol. https://doi.org/10.1186/s13059-017-1324-x (2017).

41. Miyahara, T., Nakatsuji, H. \& Sugiyama, H. Similarities and differences between RNA and DNA double-helical structures in circular dichroism spectroscopy: a SAC-CI study. J. Phys. Chem. A https://doi.org/10.1021/acs. jpca.6b08023 (2016).

42. Schade, M., Turner, C. J., Lowenhaupt, K., Rich, A. \& Herbert, A. Structurefunction analysis of the Z-DNA-binding domain Zalpha of dsRNA adenosine deaminase type I reveals similarity to the (alpha + beta) family of helix-turnhelix proteins. EMBO J. 18, 470-479 (1999).

43. Kang, Y. M. et al. NMR spectroscopic elucidation of the B-Z transition of a DNA double helix induced by the Za domain of human ADAR1. J. Am. Chem. Soc. https://doi.org/10.1021/ja902654u (2009).

44. Lee, E. H. et al. NMR study of hydrogen exchange during the B-Z transition of a DNA duplex induced by the Za domains of yatapoxvirus E3L. FEBS Lett. https://doi.org/10.1016/j.febslet.2010.10.003 (2010).
45. Lee, A. R. et al. Solution structure of the Z-DNA binding domain of PKR-like protein kinase from Carassius auratus and quantitative analyses of the intermediate complex during B-Z transition. Nucleic Acids Res. https://doi.org/ 10.1093/nar/gkw025 (2016).

46. Mathews, D. H. et al. Incorporating chemical modification constraints into a dynamic programming algorithm for prediction of RNA secondary structure. Proc. Natl Acad. Sci. USA https://doi.org/10.1073/pnas.0401799101 (2004).

47. Ha, S. C. et al. The structures of non-CG-repeat Z-DNAs co-crystallized with the Z-DNA-binding domain, hZa(ADAR1). Nucleic Acids Res. https://doi.org/ 10.1093/nar/gkn976 (2009).

48. Füchtbauer, A. F. et al. Interbase FRET in RNA: from A to Z. Nucleic Acids Res. (2019). https://doi.org/10.1093/nar/gkz812

49. Kim, S. H. et al. Unveiling the pathway to Z-DNA in the protein-induced B-Z transition. Nucleic Acids Res. https://doi.org/10.1093/nar/gky200 (2018).

50. Rich, A., Nordheim, A. \& Wang, A. H. J. The chemistry and biology of lefthanded Z-DNA. Annu. Rev. Biochem. https://doi.org/10.1146/annurev. bi.53.070184.004043 (1983).

51. Jayachandran, U., Grey, H. \& Cook, A. G. Nuclear factor 90 uses an ADAR2 like binding mode to recognize specific bases in dsRNA. Nucleic Acids Res. https://doi.org/10.1093/nar/gkv1508 (2015).

52. Tawfik, D. S. Messy biology and the origins of evolutionary innovations. Nat. Chem. Biol. https://doi.org/10.1038/nchembio.441 (2010).

53. D'Ascenzo, L., Vicens, Q. \& Auffinger, P. Identification of receptors for UNCG and GNRA Z-turns and their occurrence in rRNA. Nucleic Acids Res. https://doi.org/10.1093/nar/gky578 (2018).

54. Ng, S. K., Weissbach, R., Ronson, G. E. \& Scadden, A. D. J. Proteins that contain a functional Z-DNA-binding domain localize to cytoplasmic stress granules. Nucleic Acids Res. https://doi.org/10.1093/nar/gkt750 (2013).

55. Weissbach, R. \& Scadden, A. D. J. Tudor-SN and ADAR1 are components of cytoplasmic stress granules. RNA https://doi.org/10.1261/rna.027656.111 (2012).

56. Schwartz, T. et al. Proteolytic dissection of Zab, the Z-DNA-binding domain of human ADAR1. J. Biol. Chem. https://doi.org/10.1074/jbc.274.5.2899 (1999).

57. Klump, H. H. \& Jovin, T. M. Formation of a left-handed RNA double helix: energetics of the A-Z transition of poly $[\mathrm{r}(\mathrm{G}-\mathrm{C})]$ in concentrated sodium perchlorate solutions. Biochemistry 26, 5186-5190 (1987).

58. Freyer, M. W. \& Lewis, E. A. Isothermal titration calorimetry: experimental design, data analysis, and probing macromolecule/ligand binding and kinetic interactions. Methods Cell Biol. https://doi.org/10.1016/S0091-679X(07)84004-0 (2008).

59. Schuck, P. Size-distribution analysis of macromolecules by sedimentation velocity ultracentrifugation and Lamm equation modeling. Biophys. J. https:// doi.org/10.1016/S0006-3495(00)76713-0 (2000).

60. Voss, N. R. \& Gerstein, M. Calculation of standard atomic volumes for RNA and comparison with proteins: RNA is packed more tightly. J. Mol. Biol. https://doi.org/10.1016/j.jmb.2004.11.072 (2005).

61. Delaglio, F. et al. NMRPipe: a multidimensional spectral processing system based on UNIX pipes. J. Biomol. NMR 6, 277-293 (1995).

62. Hyberts, S. G., Milbradt, A. G., Wagner, A. B., Arthanari, H. \& Wagner, G. Application of iterative soft thresholding for fast reconstruction of NMR data non-uniformly sampled with multidimensional Poisson Gap scheduling. J. Biomol. NMR https://doi.org/10.1007/s10858-012-9611-z (2012).

63. Vranken, W. F. et al. The CCPN data model for NMR spectroscopy: development of a software pipeline. Proteins Struct. Funct. Genet. 59, 687-696 (2005).

64. Kay, L. E., Torchia, D. A. \& Bax, A. Backbone dynamics of proteins as studied by $15 \mathrm{~N}$ inverse detected heteronuclear NMR spectroscopy: application to staphylococcal nuclease. Biochemistry https://doi.org/10.1021/bi00449a003 (1989).

65. Montaville, P. et al. The PIP2 binding mode of the C2 domains of rabphilin3A. Protein Sci. https://doi.org/10.1110/ps.073326608 (2008).

66. Williamson, M. P. Using chemical shift perturbation to characterise ligand binding. Progress in Nuclear Magnetic Resonance Spectroscopy (2013). https:// doi.org/10.1016/j.pnmrs.2013.02.001

\section{Acknowledgements}

The authors thank Peter Dröge and Alekos Athanasiadis for the gift of the $6 \mathrm{x}$ His-tag (Nterminal) Za plasmid (pet-28a(+)); current and former Kieft lab and Vögeli lab members for thoughtful discussions and technical assistance; Jared Lindenberger for help with AUC measurements; the Biophysics core and NMR facilities at the University of Colorado Denver; and Pascal Auffinger, Chrysa Latrick, Ben Akiyama, and David Costantino for helpful discussions and critical reading of the manuscript. This research is funded by NSF grant 1917254 for Infrastructure Innovation for Biological Research and a start-up package from the University of Colorado to B.V.; NIH grant R35GM118070 to J.S.K.; NIH grant S10OD025020 for shared and high-end instrumentation award. The University of Colorado Anschutz Medical Campus NMR facility is partially supported by NIH grant P30CA04693. 


\section{Author contributions}

P.N. performed all experiments and data analysis with the help of S.B. (for CD, AUC, ITC) and M.H. (for NMR). P.N., J.S.K., Q.V., and B.V. interpreted the data. P.N., Q.V. and B.V. conceptualized the study, wrote and revised the manuscript. All authors provided comments on the manuscript.

\section{Competing interests}

The authors declare no competing interests.

\section{Additional information}

Supplementary information The online version contains supplementary material available at https://doi.org/10.1038/s41467-021-21039-0.

Correspondence and requests for materials should be addressed to Q.V. or B.Vög.

Peer review information Nature Communications thanks Hashim Al-Hashimi, and the other, anonymous, reviewer(s) for their contribution to the peer review of this work. Peer reviewer reports are available.
Reprints and permission information is available at http://www.nature.com/reprints

Publisher's note Springer Nature remains neutral with regard to jurisdictional claims in published maps and institutional affiliations.

\section{(c) (i)}

Open Access This article is licensed under a Creative Commons Attribution 4.0 International License, which permits use, sharing, adaptation, distribution and reproduction in any medium or format, as long as you give appropriate credit to the original author(s) and the source, provide a link to the Creative Commons license, and indicate if changes were made. The images or other third party material in this article are included in the article's Creative Commons license, unless indicated otherwise in a credit line to the material. If material is not included in the article's Creative Commons license and your intended use is not permitted by statutory regulation or exceeds the permitted use, you will need to obtain permission directly from the copyright holder. To view a copy of this license, visit http://creativecommons.org/licenses/by/4.0/.

(C) The Author(s) 2021 